\title{
AN EXPERIMENTAL STUDY ON WAVE FORCES ON A VERTICAL CYLINDER DUE TO SPILLING BREAKING AND NEAR-BREAKING WAVE GROUPS
}

\author{
Javier Murgoitio Esandi ${ }^{1}$, Eugeny Buldakov ${ }^{1}$, Richard Simons ${ }^{1}$, Dimitris Stagonas ${ }^{2}$ \\ ${ }^{1}$ UCL, Department of Civil, Environment \& Geomatic Engineering, Gower Street, London, UK \\ ${ }^{2}$ Cranfield University, Centre for Thermal Energy Systems and Materials, College Rd, Cranfield, Bedford, MK43 OAL
}

\begin{abstract}
This paper highlights the importance of spilling breaking waves in the design of offshore structures. Although wave loading on offshore structures due to non-breaking waves has been extensively studied, wave loading due to breaking waves is uncertain and not very well understood. Plunging breaking waves in deep water are very unusual, whereas spilling breaking waves are very common in extreme seas. Nevertheless, no significant research efforts have been made to study the effects of spilling breaking waves. The present study addresses this, comparing the wave loading from highly nonlinear non-breaking waves and spilling breaking waves. Focused wave groups have been used to generate the non-breaking and spilling breaking wave conditions in a wave tank. The experiments have shown that spilling breaking waves generate significantly larger forces on the cylindrical model than highly non-linear non-breaking waves of equivalent size. This is shown to be due to the direct excitation at high frequency as well as the resonant and impact excitation of higher natural frequency modes. It is concluded that spilling breaking waves can generate very significant forces and should therefore be considered in the design of offshore structures.
\end{abstract}

\section{Keywords}

Wave-structure interactions, wave groups, extreme waves, breaking waves

\section{Introduction}

The design of any offshore structure depends on reliable estimations of water surface elevation and wave loading due to extreme waves. Throughout history, extreme waves have been responsible for many marine accidents. It is evident that these events should be carefully considered in the design of offshore structures. Many studies show that extreme waves can be represented as wave groups (e.g. Christou \& Ewans, 2014). The question regarding the shape of the surface elevation around extreme wave crests was first considered by Lindgren (1970), who showed that the profile of an extreme wave in a random Gaussian sea can be adequately represented by a focussed wave group. This has been reproduced by later studies such as Boccotti (1982). Using these concepts, Tromans et al. (1991) introduced a practical model to apply focused wave groups as design waves; this is known as the NewWave model. This improved the ability to predict the surface elevation, velocities and accelerations induced by extreme ocean waves. Later studies, such as Phillips et al. (1993) and Christou \& Ewans (2014), have confirmed this theory through analysis of field measurement data.

Wave groups are often used as input waves in experimental studies of wave-structure interaction. Experimental generation of focused wave groups has been the focus of many studies in recent decades and many methodologies have been used to reproduce them in a wave tank (Baldock \& Swan, 1996; Chaplin, 1996; Schmittner et al, 2009). Baldock et al. (1996) and Baldock \& Swan (1996) used linear wave theory to calculate the phases of components in the wave group and to focus them at the target location. A downstream shift of the focusing point was found in the generation of focused wave groups. This shift was corrected by iteratively changing the focal position of the linear wave group until the focusing point and the target location were matched. Separately, iterative approaches to correct the inputs to the wave generator to achieve the match between the focal location of the wave groups and the target location have been developed and applied (Chaplin, 1996; Fernández et al., 2014; Schmittner et al., 2009; Stagonas et al., 2014). These methods use the measurements of previously generated focused wave groups to correct the input of the next focused wave group to be generated. Buldakov et al. (2017) presented an iterative technique for the controlled generation of spilling breaking waves and this is the methodology used in the present study. 
The nonlinear nature of extreme waves leads to the generation of a high frequency response in the structures with which they interact. High-frequency wave loads can have damaging consequences for offshore structures and have been extensively investigated. Extreme wave loads can be decomposed into the fundamental component at the peak frequency of the incoming wave field and higher order harmonics. Grue et al. (1993), Huseby \& Grue (2000) and Chen et al. (2018) studied the higher order harmonic wave forces on a vertical cylinder and concluded that these can have a significant effect in the ringing response of the structure. In fact, Chen et al. (2018) found that the higher order harmonics can account for up to $60 \%$ of the total wave force.

The occurrence of extreme waves is invariably associated with wave breaking. The focus of the research on breaking wave loading has been on depth-limited breaking in shallow and intermediate water conditions. This is mostly due to the growth seen in deployment of bottom-fixed offshore wind turbines. A large number of experimental studies consider breaking regular waves on a slope and their interaction with cylindrical structures (e.g. Apelt \& Piorewicz, 1987; Luck \& Benoit, 2005; Choi et al. 2015). Wave parameters and slopes satisfying both spilling and plunging breaking conditions have been studied. The kinematics of such waves satisfying spilling breaking conditions was studied numerically by Alagan Chella et al. (2015) who simulated conditions of the experimental study of Ting \& Kirby (1996). They observed large scale spilling breaking and breaking of a transitional type with considerable plungers. An experimental study of cylinder loads for both regular and irregular random waves experiencing depth-limited breaking on a slope was performed by Chakrabarti et al. (1997). Their results were used for validation of numerical models and further studies by Alagan Chella et al. (2019) for regular wave cases and by Aggarwal et al. (2019) for irregular waves. Large scale plunging and spilling breakers affecting a significant part of the wave crest were observed in these studies.

For offshore structures in deep and intermediate water it is appropriate to consider steepness-limited breaking. Experimentally such breaking waves can be generated using focussed wave groups or within long random wave sequences corresponding to steep sea states. Many studies of breaking wave impacts use asymmetric wave groups with a large-scale plunging breaker comparable with the wave height (e.g. Chan et al. 1995; Wienke \& Oumeraci, 2005; Hildebrandt \& Schlurmann, 2012). A brief review of works on wave impact forces due to large scale breaking can be found in Alagan Chella et al. (2012). This breaking type is common for very large wave events with low return periods. For example, Kim \& Kim (2003) experimentally reproduced a Draupner freak wave using the amplitude spectrum of the real wave. The resulting wave group experienced large scale plunging breaking. They recorded the wave kinematics and measured the force generated by the wave on a truncated cylinder.

However, NewWave theory suggests that the highest waves in a moderately severe sea state are focussed or nearly focussed symmetrical waves experiencing spilling breaking with a sharp crest. An offshore structure designed for a standard storm is more likely to interact with such waves. To the best of our knowledge, very few published works consider such waves and no systematic study of their interaction with structures is currently available. The following recent papers may be mentioned. Ghadirian et al. (2016) performed an experimental and numerical study of breaking wave groups around monopiles. Horizontal force, elevation and pressure distribution on the monopiles were measured. A limited number of cases was considered and the effects of breaking were not clearly identified. The main focus of the paper was on experimental validation of a numerical model. The experimental work of Chen et al. (2018) considered focussed wave groups with a JONSWAP spectrum of increasing steepness to generate non-breaking, spilling and plunging breaking waves interacting with a cylinder. Peak and trough focussed waves were generated and modal decomposition of the force up to fifth order was performed. However, the paper does not place emphasis on breaking effects.

It is well known that the impact of breaking waves causes a considerable increase in force on a structure. For example, Stansby et al. (2013) compared the experimental results of Luck \& Benoit (2005) with forces calculated using Morrison's equation and stream function theory for regular waves. For different values of the depth parameter $k d$ the force measured in the experiment was between 1 and 2.8 times larger than the force calculated for the non-breaking kinematics. Kim \& Kim (2003) compared the measured cylinder force of their experimental Draupner wave with the force generated by a non-breaking regular wave of an equivalent size. The peak force for a breaking wave group was found to be 2.8 times larger than for a regular non-breaking wave. However, they erroneously attribute force oscillations after the impact to the breaking wave turbulence. In fact, these oscillations are due to the dynamic structural response which is at least partly responsible for the significant increase of structural loads. To isolate this effect Choi et al. (2015) compared their experimental measurements with the results of CFD simulation for an absolutely solid structure. This allowed calculation of the Dynamic Amplification Factor (DAF) due to structural response caused by the breaking wave impact. For the case studied, 


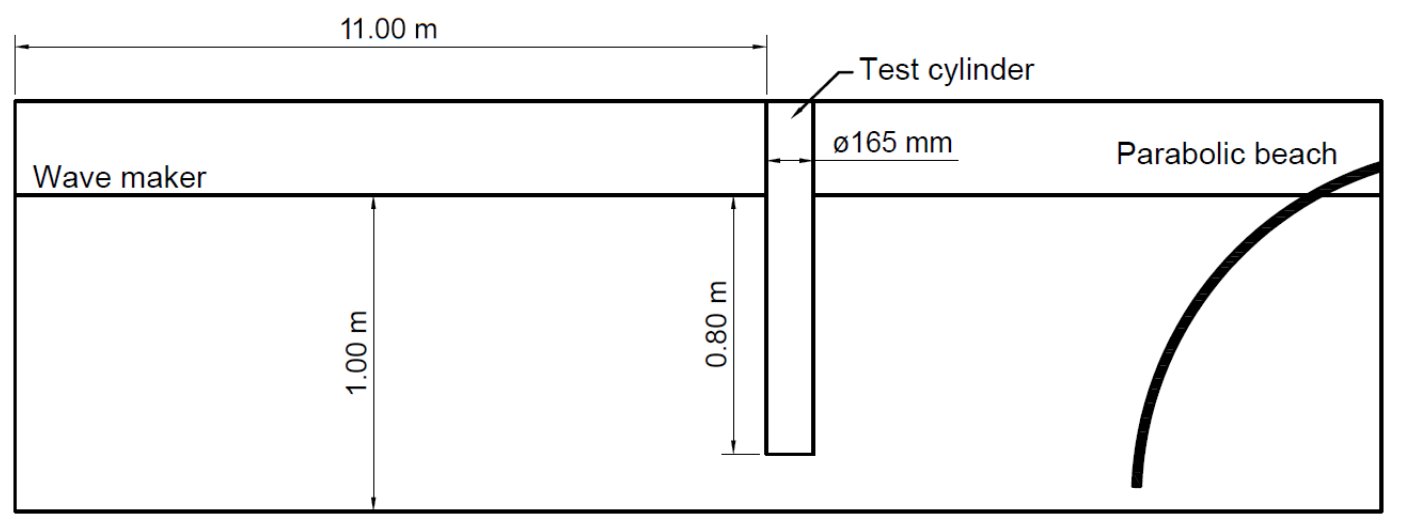

Figure 1: Experimental layout.

the value of DAF was approximately 1.5. Suja-Thauvin et al. (2017) carried out an experimental study using a scale model of a monopile wind turbine in severe irregular wave conditions. They measured 6 load components on a flexible model with the scaled 1st and 2nd natural modes and on a rigid model. The flexible model was used to study the structural response with an emphasis on ringing and the response to rupture. The rigid model was used to measure the quasi-static response. Load statistics and response to individual wave events were analysed. The highest loads were recorded when the breaking triggered the second structural mode. For such events, 40 to $50 \%$ of the total load was due to the quasi-static response, 30 to $40 \%$ to the dynamic response of the first mode and up to $20 \%$ to the dynamic response of the second mode.

The purpose of the present experimental study is to investigate the wave loading from spilling breaking waves, adopting a realistic representation of extreme breaking waves and qualitatively describing the nature of the loading. Non-breaking strongly nonlinear waves of slightly smaller amplitude have also been tested for comparison, to analyse the effect of spilling breakers in wave loading. The structure of the paper is as follows. In Section 2 we describe the experimental set up and input wave field, the methodology used to generate the focused wave groups and the method of spectral decomposition. In Section 3 we present and analyse the experimental results of nonbreaking and breaking wave loading for the focused wave groups generated. Finally, in Section 4 we analyse further the results and give the main conclusions.

\section{Experimental set-up, test cases and methodologies}

The tests were carried out in the ocean tank in the UCL Mechanical Engineering Department. The tank measures $17 \mathrm{~m}$ long, $2.5 \mathrm{~m}$ wide and $1.3 \mathrm{~m}$ deep. All the experiments were carried out with a water depth of $1 \mathrm{~m}$. One end of the tank has an array of seven flap wave makers and a full width parabolic beach is fitted across the other end. Wave propagation was monitored by 2 resistance wave probes installed at locations $3 \mathrm{~m}$ and $11 \mathrm{~m}$ from the wave generator and $40 \mathrm{~cm}$ from the tank sidewall. First, a series of tests without a model was performed to generate focussed wave groups. Then, a truncated cylinder with a diameter of $165 \mathrm{~mm}$ was installed as the test structure. The front line of the cylinder was located $11 \mathrm{~m}$ from the wave generator at the centre line of the tank (Figure 1). The cylinder was fixed to an aluminium member along its centreline. This aluminium member was fixed to a steel beam crossing the tank side-to-side with two load cells separated by $150 \mathrm{~mm}$. A schematic of the model is illustrated in Figure 2. The first natural frequency of the structural system tested was $6.5 \mathrm{~Hz}$.

The methodology used to generate focused wave groups in this study is presented by Buldakov et al. (2017). It involves an iterative procedure that corrects the input wave spectra to the wave generator at each iteration. The first focused wave group is generated using linear wave theory and the dephasing due to nonlinear wave-wave interaction is corrected thereafter. The corrections to input amplitudes and phases are defined as follows

$$
a_{\text {in }}^{n}\left(f_{i}\right)=a_{\text {in }}^{n-1}\left(f_{i}\right) a_{\text {tgt }}\left(f_{i}\right) / a_{\text {out }}^{n-1}\left(f_{i}\right) ; \quad \phi_{\text {in }}^{n}\left(f_{i}\right)=\phi_{\text {in }}^{n-1}\left(f_{i}\right)+\left(\phi_{\text {tgt }}\left(f_{i}\right)-\phi_{\text {out }}^{n-1}\left(f_{i}\right)\right),
$$

where $a_{i n}^{n}\left(f_{i}\right)$ and $\phi_{i n}^{n}\left(f_{i}\right)$ are the amplitude and phase components of the input spectrum at frequency $f_{i}$ for the $\mathrm{n}^{\text {th }}$ iteration; $a_{\text {out }}^{n}\left(f_{i}\right)$ and $\phi_{\text {out }}^{n}\left(f_{i}\right)$ are the amplitude and phase components of the corresponding output spectrum, and $a_{\text {tgt }}\left(f_{i}\right)$ and $\phi_{\text {tgt }}\left(f_{i}\right)$ are the target spectral components. The linearised surface elevation spectrum 


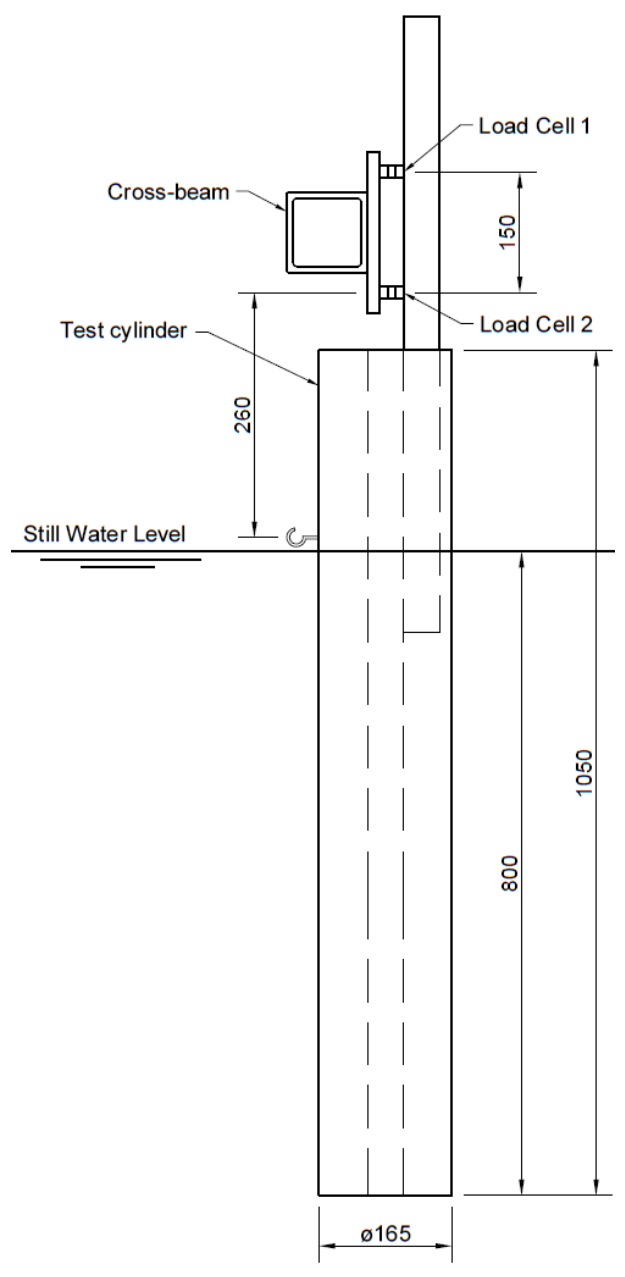

Figure 2: Experimental model set-up (units: $\mathrm{mm}$ ).

is used as the output which, after completing the iterations, should match a specified target. The linearised spectrum is obtained by the wave decomposition methodology described further in this section. Using a linearised spectrum instead of a full spectrum reduces the nonlinearity of the transfer function and improves the convergence of corrections (Buldakov et al., 2017). The second key feature of this methodology is using outputs at different positions for phase and amplitude iterations. The amplitude spectrum is measured near the wave generator and the phase spectrum is measured at the focus position. Buldakov et al. (2017) found that this approach improves the convergence of the iterations. In this study the amplitude matching position is $3 \mathrm{~m}$ from the wave generator and the focal position is $11 \mathrm{~m}$ from the wave generator.

We use Gaussian spectra as targets. Although the Gaussian spectrum is not found as a natural sea state, the methodology applied makes it suitable for the representation of realistic sea states. Indeed, the amplitude spectrum of a generated wave is matched with the target Gaussian spectrum at the position $3 \mathrm{~m}$ from the wave generator. By the time the wave group arrives at the focal position $11 \mathrm{~m}$ from the wave generator, wave energy has been transferred from lower to higher frequencies due to high-order non-linear wave-wave interactions. The result is a spectrum of a more realistic shape at the focus position. This can be observed in Figure 3(a, b), which shows examples of the non-dimensional linearised amplitude spectra measured at 3 and $11 \mathrm{~m}$ from the wave generator. At the focal position, all the components of the target wave are in phase, that is to say, the generated wave is supposed to be focused. As explained below, wave groups with 4 different target phase values $\Delta \varphi$ are generated. An example in Figure 3(c,d) demonstrates good focussing for a peak-focussed wave $(\Delta \varphi=0)$.

The wave groups generated during the experiments have spectra with peak periods of $1.2 \mathrm{~s}$ and $1.4 \mathrm{~s}$. On a scale of 1/100, our experiments simulate sea states with peak periods of 12 and $14 \mathrm{~s}$ at $100 \mathrm{~m}$ depth, which can be considered as reasonable conditions for extreme sea states (e.g. Christou \& Ewans, 2014). The amplitude of a focussed target wave $\left(\mathrm{A}_{\mathrm{f}}\right)$ is used as a nominal measure of the amplitude of the generated wave and is an input 
Table 1: Incoming wave fields.

\begin{tabular}{|c|c|c|c|c|c|c|c|}
\hline $\mathrm{T}_{\mathrm{p}}(\mathrm{sec})$ & $\mathrm{f}_{\mathrm{p}}(\mathrm{Hz})$ & $\lambda_{\mathrm{p}}(\mathrm{m})$ & $\mathrm{k}_{\mathrm{p}}\left(\mathrm{m}^{-1}\right)$ & $\mathrm{A}_{\mathrm{f}}(\mathrm{cm})$ & $\mathrm{k}_{\mathrm{p}} \mathrm{A}_{\mathrm{f}}$ & Wave behaviour & Case \\
\hline \multirow{5}{*}{1.2} & \multirow{5}{*}{0.83} & \multirow{5}{*}{2.23} & \multirow{5}{*}{2.81} & 8.4 & 0.236 & Non-breaking & T12NB1 \\
\hline & & & & 9.1 & 0.256 & Non-breaking & T12NB2 \\
\hline & & & & 9.8 & 0.275 & Non-breaking & T12NB3 \\
\hline & & & & 10.15 & 0.285 & Breaking & T12BR1 \\
\hline & & & & 10.5 & 0.295 & Breaking & T12BR2 \\
\hline \multirow{5}{*}{1.4} & \multirow{5}{*}{0.71} & \multirow{5}{*}{2.97} & \multirow{5}{*}{2.11} & 11.7 & 0.247 & Non-breaking & T14NB1 \\
\hline & & & & 12.6 & 0.266 & Non-breaking & T14NB2 \\
\hline & & & & 13.5 & 0.285 & Non-breaking & T14NB3 \\
\hline & & & & 13.95 & 0.294 & Breaking & T14BR1 \\
\hline & & & & 14.4 & 0.304 & Breaking & T14BR2 \\
\hline
\end{tabular}

parameter of the iterative procedure. For each wave period, we use the iterative procedure to create a sequence of waves of different amplitudes. We start from a relatively small wave, then increase the amplitude in small increments. An upscaled spectrum of a previously generated wave is used to start iterations for the next wave in a sequence. This improves the convergence of iterations for large waves and reduces the total number of iterations. The range of waves generated covers steep non-breaking waves and breaking waves of various intensity. Five waves for each period are selected for further analysis and for testing with the installed model. Table 1 shows the parameters of the waves selected and names of the wave cases used for the rest of the paper. The wave length $\left(\lambda_{\mathrm{p}}\right)$ and wave number $\left(\mathrm{k}_{\mathrm{p}}\right)$ are linear values corresponding to the peak period.

In this paper the spectral decomposition method, also known as harmonic separation method, is used to analyse the harmonic structure of the surface elevation and of the wave load on the cylinder. We use the 4-wave decomposition, which allows a more efficient separation of the high-order harmonic components (Fitzgerald et al., 2014). We follow the version of the method introduced by Buldakov et al. (2017). Although the theoretical applicability of this method is restricted to non-breaking waves, Buldakov et al. (2017) demonstrate its practical applicability for waves with weak local breaking. Therefore, it was found appropriate to use it for this study. The method can be formulated as follows

$$
\begin{aligned}
& S_{0}+S_{4}+\cdots=\left(s_{0}+s_{1}+s_{2}+s_{3}\right) / 4 ; \\
& S_{1}+S_{5}+\cdots=\left(s_{0}-i s_{1}-s_{2}+i s_{3}\right) / 4 ; \\
& S_{2}+S_{6}+\cdots=\left(s_{0}-s_{1}+s_{2}-s_{3}\right) / 4 ; \\
& S_{3}+S_{7}+\cdots=\left(s_{0}+i s_{1}-s_{2}-i s_{3}\right) / 4,
\end{aligned}
$$

where $s_{0}, s_{1}, s_{2}$, and $s_{3}$ are the complex-valued spectra of the original signal (force or elevation) for phase shifts $\Delta \varphi=0,90^{\circ}, 180^{\circ}$ and $270^{\circ}$ respectively, and $S_{0}$ to $S_{7}$ are the spectra for separated harmonic components. The spectral component $S_{0}$ represents low-frequency nonlinear sub-harmonics, which consists mainly of the secondorder difference term of a Stokes-type perturbation expansion. The component $S_{1}$ represents the first-order harmonic sometimes referred to as the linear component. We use this spectral component for surface elevation as the output spectrum for the iterative wave generation procedure described above. The rest of the components represent higher-order nonlinear components. In this work we use the spectral decomposition method to analyse force harmonics from $\mathrm{S}_{0}$ to $\mathrm{S}_{5}$, which covers the frequency range up to $5 \mathrm{~Hz}$. For the separation of harmonic responses beyond $5 \mathrm{~Hz}$, the measured force spectrum has been separated into the frequency ranges corresponding to different structural excitation regimes. Then, the inverse Fourier transform has been calculated considering only the measured spectrum within each frequency range.

\section{Results}

\subsection{Focused Wave Groups}

Five wave amplitudes were generated for each peak period considered in this study. Table 1 presents the values of linear focus amplitude used as input parameters for wave generation and the corresponding values of wave steepness. However, these parameters cannot be measured directly from real sea observations or from 

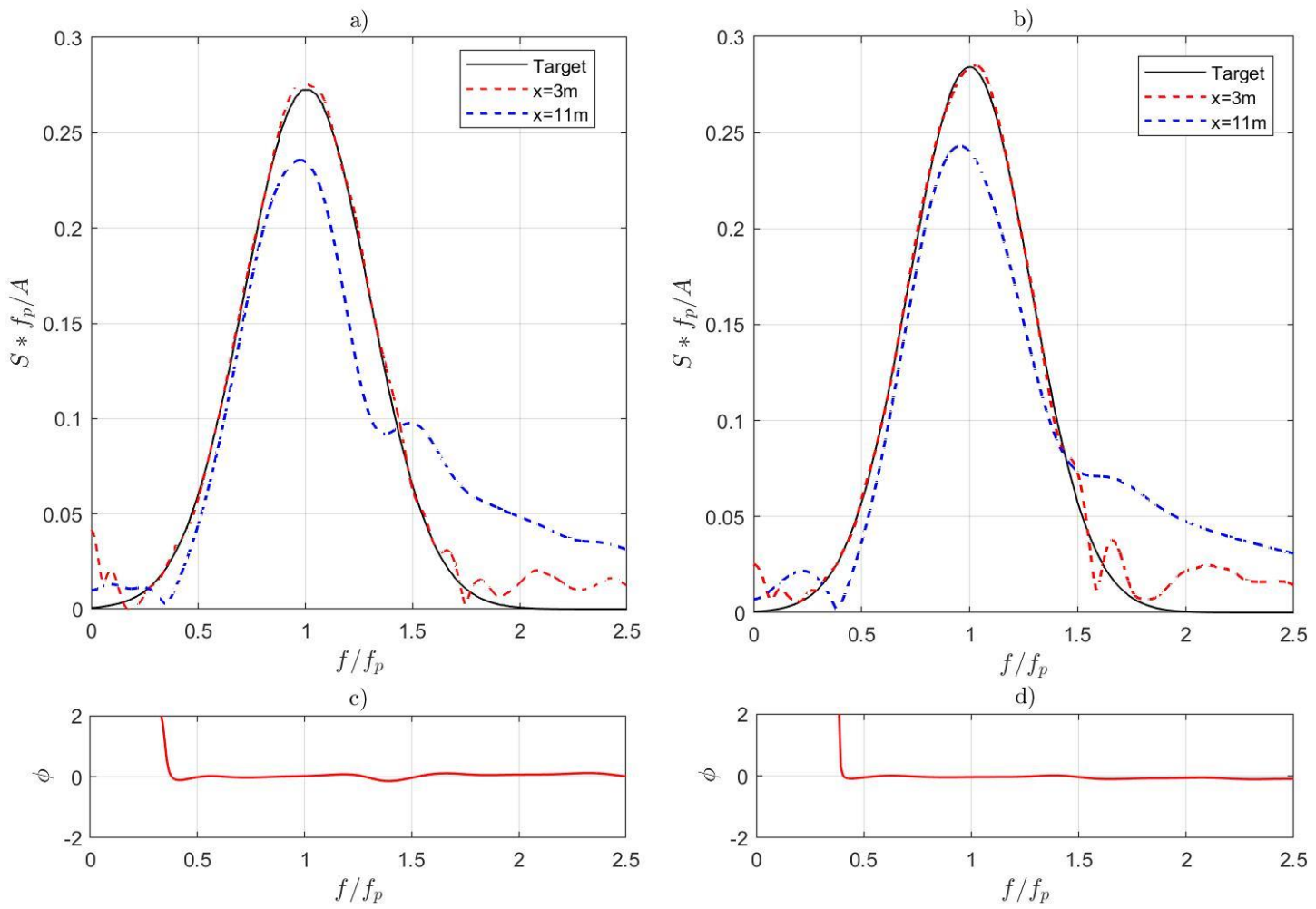

Figure 3: (Colour online) Linearised spectra for focused nonlinear wave groups for cases a) T12NB3 amplitude spectrum, b) T14NB3 amplitude spectrum, c) T12NB3 phase spectrum and d) T14NB3 phase spectrum.

Table 2: Summary of measured wave parameters.

\begin{tabular}{lllllll}
\hline Case & $\mathrm{k}_{\mathrm{p}} \mathrm{A}_{\mathrm{f}}$ & $\mathrm{\eta}_{\mathrm{c}}(\mathrm{cm})$ & $\zeta$ & $\mathrm{H}(\mathrm{cm})$ & $\mathrm{k}_{\mathrm{p}} \mathrm{H} / 2$ & $\mathrm{H} / \lambda_{\mathrm{p}}$ \\
\hline T12NB1 & 0.236 & 10.38 & 0.235 & 14.82 & 0.208 & 0.066 \\
$\mathrm{~T} 12 \mathrm{NB} 2$ & 0.256 & 11.16 & 0.226 & 15.70 & 0.221 & 0.070 \\
$\mathrm{~T} 12 \mathrm{NB} 3$ & 0.275 & 12.71 & 0.297 & 17.55 & 0.247 & 0.079 \\
$\mathrm{~T} 12 \mathrm{BR} 1$ & 0.285 & 13.63 & 0.342 & 18.83 & 0.265 & 0.084 \\
$\mathrm{~T} 12 \mathrm{BR} 2$ & 0.295 & 13.49 & 0.284 & 19.23 & 0.270 & 0.086 \\
\hline T14NB1 & 0.247 & 13.72 & 0.173 & 20.42 & 0.215 & 0.069 \\
T14NB2 & 0.266 & 15.37 & 0.220 & 22.50 & 0.237 & 0.076 \\
T14NB3 & 0.285 & 16.71 & 0.238 & 23.87 & 0.252 & 0.080 \\
T14BR1 & 0.294 & 19.10 & 0.369 & 26.31 & 0.278 & 0.089 \\
T14BR2 & 0.304 & 18.45 & 0.281 & 26.00 & 0.274 & 0.087 \\
\hline
\end{tabular}

experimental measurements of a single wave. Table 2 gives a summary of amplitude and steepness parameters directly measured in the experiments for crest-focussed waves. They include crest elevation at focus location $\left(\eta_{c}\right)$, relative non-linear growth of crest elevation $\left(\zeta=\eta_{c} / A_{f}-1\right)$, trough to crest wave height at focus $(H)$ and the corresponding values of wave steepness. It is appropriate to use a zero-crossing period in conjunction with this wave height. However, it is found to be practically identical to the peak period. Therefore, we keep using the values of $T_{p}$ from Table 1 . The values of steepness $k_{p} A_{f}$ are given as a reference.

As shown in Table 2, due to the non-linear growth, the crest elevation is between $17 \%$ and $37 \%$ higher than the linear focal amplitude. Smaller non-breaking waves show slight non-linear crest growth around $\zeta=0.2$. As the linear amplitude increases, the crest becomes highly non-linear. The non-linear crest growth becomes increasingly significant and the crest starts increasing rapidly for the largest non-breaking wave. The crest elevation continues to grow for the smallest breaking wave, but stronger breaking causes its reduction. The critical steepness associated with incipient wave breaking lies between $\mathrm{k}_{\mathrm{p}} \mathrm{A}_{\mathrm{f}}=0.275$ and 0.285 for $\mathrm{T}_{\mathrm{p}}=1.2 \mathrm{sec}$ and between 0.285 and 0.294 for $T_{p}=1.4 \mathrm{sec}$. The experimental study of wave groups with constant amplitude spectra by Rapp \& Melville (1990) gives the critical steepness of about 0.25. Chaplin (1996) reported the values of critical steepness of 0.265 and 0.3 for wave groups of constant amplitude and constant steepness spectra, respectively. The steepness based on the trough to peak wave height is considerably smaller than $k_{p} A_{f}$, as has also been 


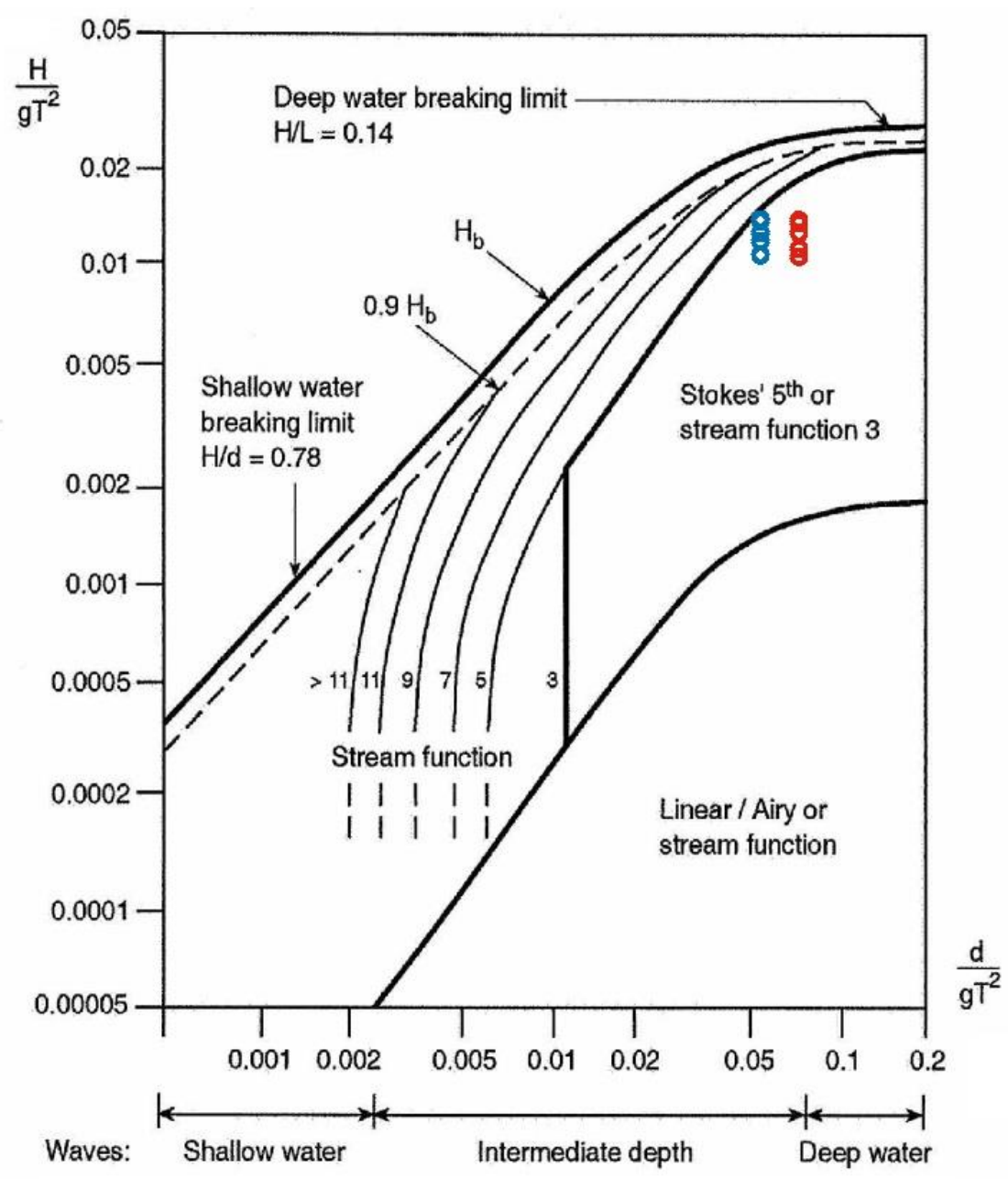

Figure 4: (Colour online) Ranges of validity for various wave theories (DNVGL, 2017). Red and blue markers represent wave sets for $T_{p}=1.2 \mathrm{sec}$ and $T_{p}=1.4 \mathrm{sec}$, respectively.

observed by Rapp \& Melville (1990). Although the crest of a nonlinear wave is higher, its trough becomes shallower. More important, the trough occurs before the focus point, where the height of the wave group envelope is less than its height at the focus. Values of critical steepness for regular waves are normally used in engineering practice. In deep water they are $\mathrm{kA}=0.44$ and $\mathrm{H} / \lambda=0.14$ (e.g. $\mathrm{DNVGL}, 2017$ ). The values observed for wave groups, which also apply to extreme events in irregular seas, are considerably lower. In accordance with the recommendations of DNVGL (2017), the waves considered in this study are not classified as breaking waves and, according to Figure 4, they are described by $5^{\text {th }}$ order Stokes theory. As demonstrated by Kim \& Kim (2003) and Stansby et al. (2013), for breaking waves this can lead to considerable underestimation of the force acting on the cylinder. The same observation is reinforced in this study.

Figure 5 shows the surface elevation time-histories for peak focussed waves scaled by the linear target amplitude. Figure 5(a) and Figure 5(b) show the experimental cases generated with $\mathrm{T}_{\mathrm{p}}=1.2 \mathrm{sec}$. Figure 5(a) shows the non-dimensional surface elevation for the three non-breaking waves. Here, it can be observed that the profile of the two smallest waves matches well and that there is a clearly larger non-linear crest growth for the largest non-breaking wave. Figure 5(b) shows the non-dimensional surface elevation for the two spilling breaking waves and the largest non-breaking wave. For breaking waves, the shape of the crest does not match. This is due to the unstable nature of these crests. We can see how the slope of the crest increases as the amplitude increases and, despite the decreasing maximum elevation, the largest breaking wave shows the steepest crest slope. Similar behaviour can be observed in Figure 5(c) and Figure 5(d) for the wave set generated with $\mathrm{T}_{\mathrm{p}}=1.4 \mathrm{sec}$. Figure 5(c) shows the non-dimensional surface elevation for the three non-breaking waves. Here, the non-linear crest height increases from the first to the second wave group generated and the non-dimensional wave profile is similar for the second and third wave groups. It is also seen that the smallest breaking wave is the first wave showing a larger 

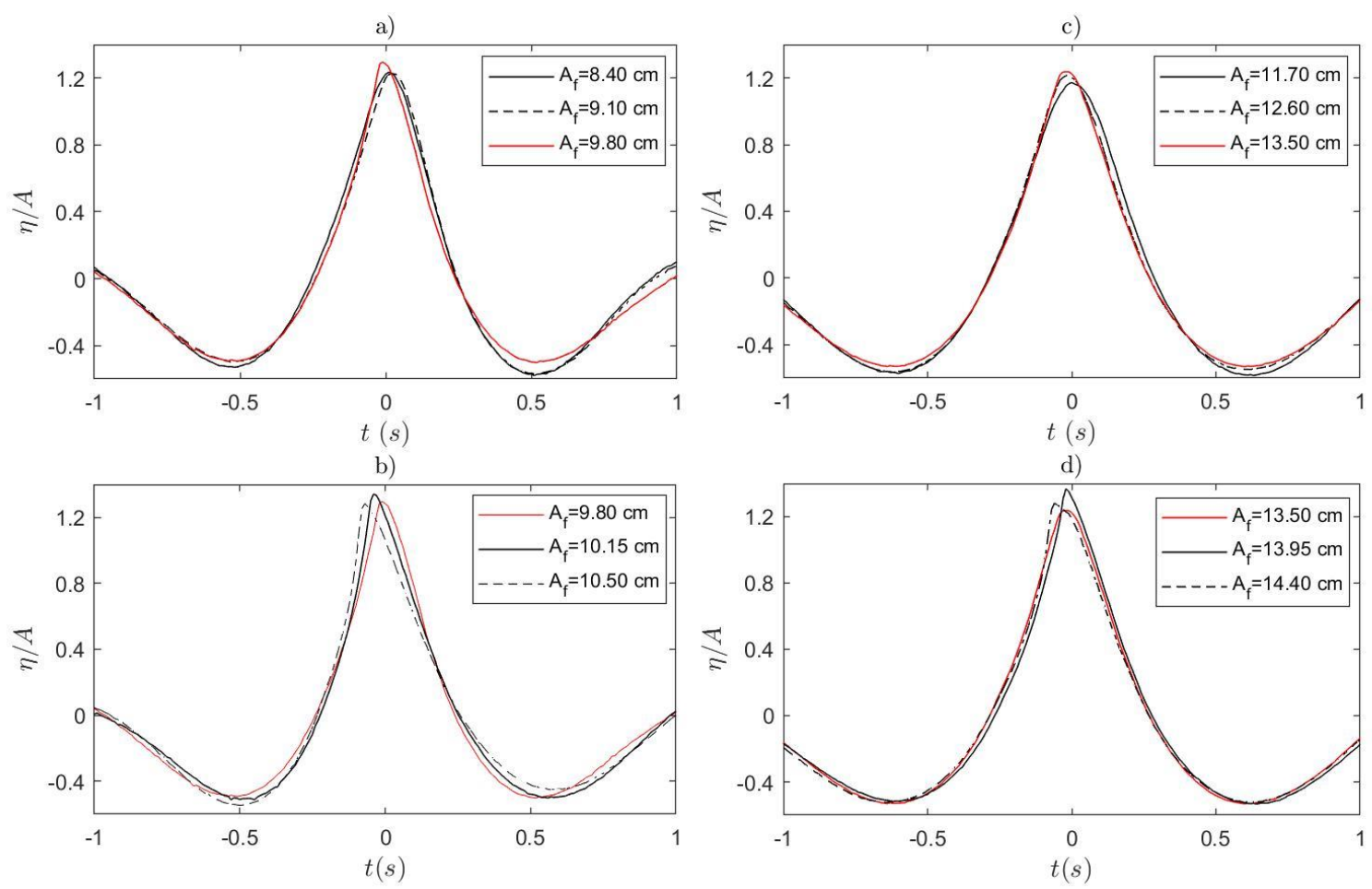

Figure 5: (Colour online) Time histories of peak-focused wave groups at the focus position for cases: a) $\mathrm{T}_{\mathrm{p}}=1.2 \mathrm{sec}$, nonbreaking; b) $T_{p}=1.2 \mathrm{sec}$, breaking and largest non-breaking; c) $\mathrm{T}_{\mathrm{p}}=1.4 \mathrm{sec}$, non-breaking; and d) $\mathrm{T}_{\mathrm{p}}=1.4 \mathrm{sec}$, breaking and largest non-breaking. The red line shows the highest non-breaking wave.

non-linear crest growth. Figure 5(d) shows the non-dimensional surface elevation for the two spilling breaking waves and the largest non-breaking wave. As observed for the previous wave set, the slope of the crest increases as the amplitude increases and the largest spilling breaking wave shows the steepest crest slope. The goal of these tests was to obtain well-focused waves of increasing steepness that show non-breaking and spilling breaking behaviour and have similar shapes and amplitudes. This was achieved for both sets of waves with $\mathrm{T}_{\mathrm{p}}=1.2 \mathrm{sec}$ and $\mathrm{T}_{\mathrm{p}}=1.4 \mathrm{sec}$.

\subsection{Forces on a Vertical Cylinder Imposed by Focused Wave Groups}

The main interest of this study is to analyse the horizontal force imposed on a cylindrical model by spilling breaking waves compared to nearly breaking waves. As this study considers only horizontal forces, these will be referred to as "forces". When we talk about a maximum force, we mean the force acting in the direction of wave propagation, because it is the direction of the breaking impact force. The total forces imposed by nearly breaking and breaking waves are compared using the crest-focused wave groups introduced above. The comparison is carried out using spectral decomposition of the imposed force, the force at different frequency ranges then compared for both types of wave. This frequency analysis is performed in two parts. The first considers the forces below the ringing response frequency around $5-7.5 \mathrm{~Hz}$ and includes first- to fifth-order force harmonics. The second considers the forces at and higher than the ringing response frequency by analysing the frequency ranges identified in the natural frequency test.

Three repetitions for smaller non-breaking waves and four for the largest non-breaking wave and the breaking waves were carried out. Table 3 shows a summary of the maximum forces measured for the crest focused wave groups of all the cases studied. As mentioned before, there is good repeatability among the repetitions carried out. In fact, the deviation among the maximum forces measured during the various repetitions is smaller than $3 \%$ of the total force. The second repetition was used to represent the wave forces in this study and to perform the spectral analysis of the forces imposed by the wave group. This is considered acceptable due to the good repeatability of the measured forces and the purpose of this study, which is a qualitative analysis of the wave forces.

Figure 6 shows a comparison between the surface elevation and the wave force time histories for two nonbreaking and two breaking waves corresponding to different peak periods. The force and surface elevation time 
Table 3: Maximum forces measured for crest focused cases.

\begin{tabular}{lllllll}
\hline \multirow{3}{*}{ Case } & \multicolumn{3}{l}{ Maximal force $(\mathrm{N})$ at each repetition } & \multicolumn{2}{l}{$\begin{array}{l}\text { Average } \\
\text { Force }(\mathrm{N})\end{array}$} & Deviation (N) \\
\cline { 2 - 5 } & 1 & 2 & 3 & 4 & 27.5 & 0.09 \\
\hline T12NB1 & 27.42 & 27.49 & 27.6 & - & 30.75 & 0.38 \\
T12NB2 & 31.19 & 30.51 & 30.54 & - & 34.99 & 0.92 \\
T12NB3 & 35.64 & 35.92 & 34.21 & 34.19 & 43.54 & 1.23 \\
T12BR1 & 45.37 & 42.91 & 42.71 & 43.18 & 51.29 & 0.88 \\
T12BR2 & 50.63 & 50.66 & 52.5 & 51.35 & 39.21 & 0.19 \\
T14NB1 & 39.09 & 39.12 & 39.43 & - & 45.4 & 0.27 \\
T14NB2 & 45.15 & 45.64 & 45.58 & - & 49.03 & 0.63 \\
T14NB3 & 49.65 & 49.38 & 48.85 & 48.22 & 58.1 & 0.9 \\
T14BR1 & 57.13 & 57.7 & 59.21 & 58.37 & 91.65 & 2.11 \\
T14BR2 & 89.58 & 90.11 & 93.14 & 93.76 & & \\
\hline
\end{tabular}
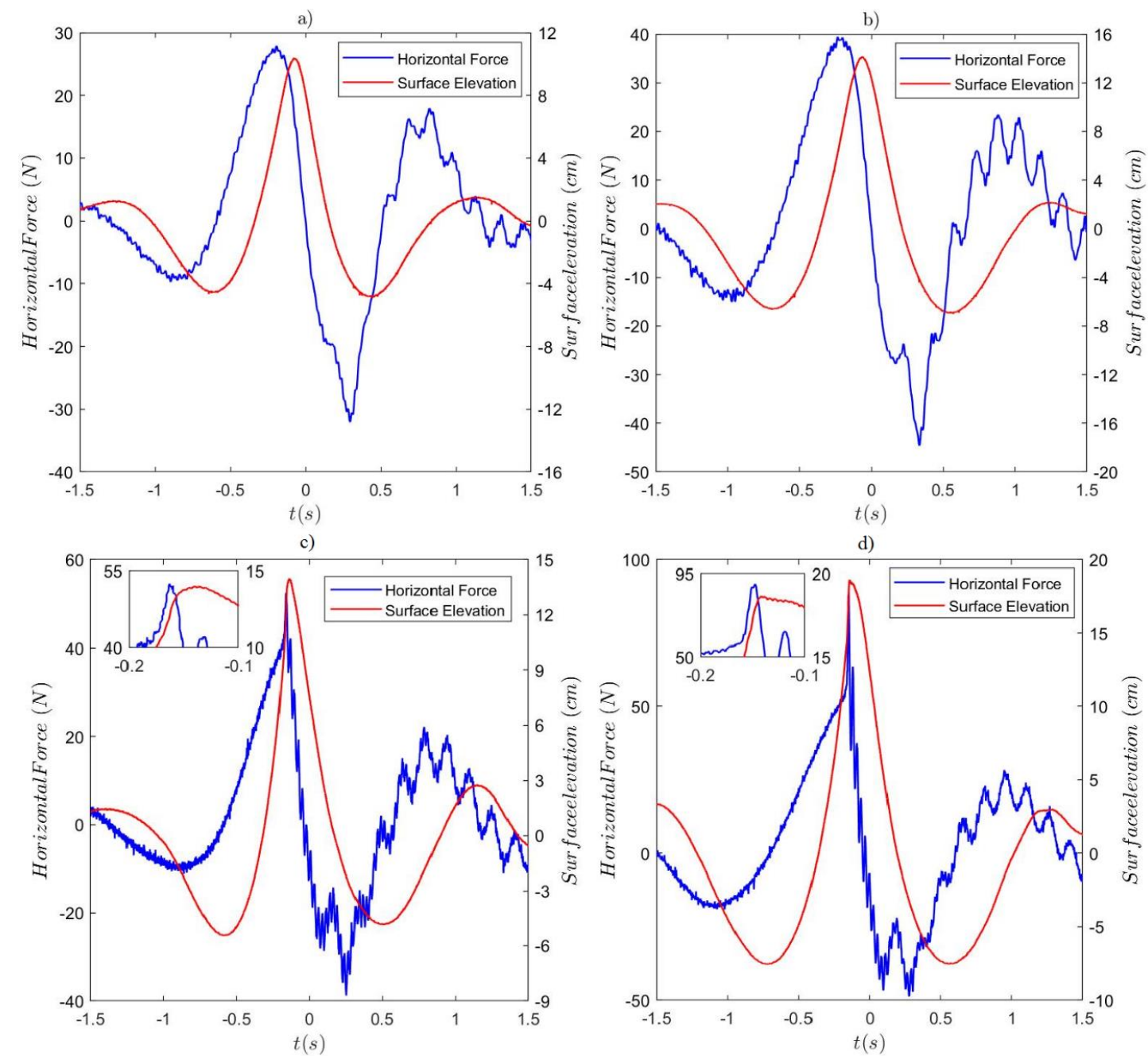

Figure 6: (Colour online) Force and surface elevation time histories for cases a) T12NB1, b) T14NB1 c) T12BR2 and d) T14BR2

histories presented in Figure 6(a, b) are out of phase by approximately $\pi / 2$, which is typical for inertia dominated loads. For breaking wave cases illustrated in Figure 6(c, d), the inertia dominated flow regime can be observed for wave peaks and troughs away from the main wave crest. However, the maximum force imposed by these waves occurs when the crest of the wave hits the cylinder. This is because the maximum force is dominated by the impact of the wave crest. Therefore, Figure 6 provides evidence that frequent events such as spilling breaking waves can change the nature of the wave loading and generate much greater forces than would be expected without breaking. It can be seen that these waves excite the structure at high frequencies, which is typical of impact forces. 
a)

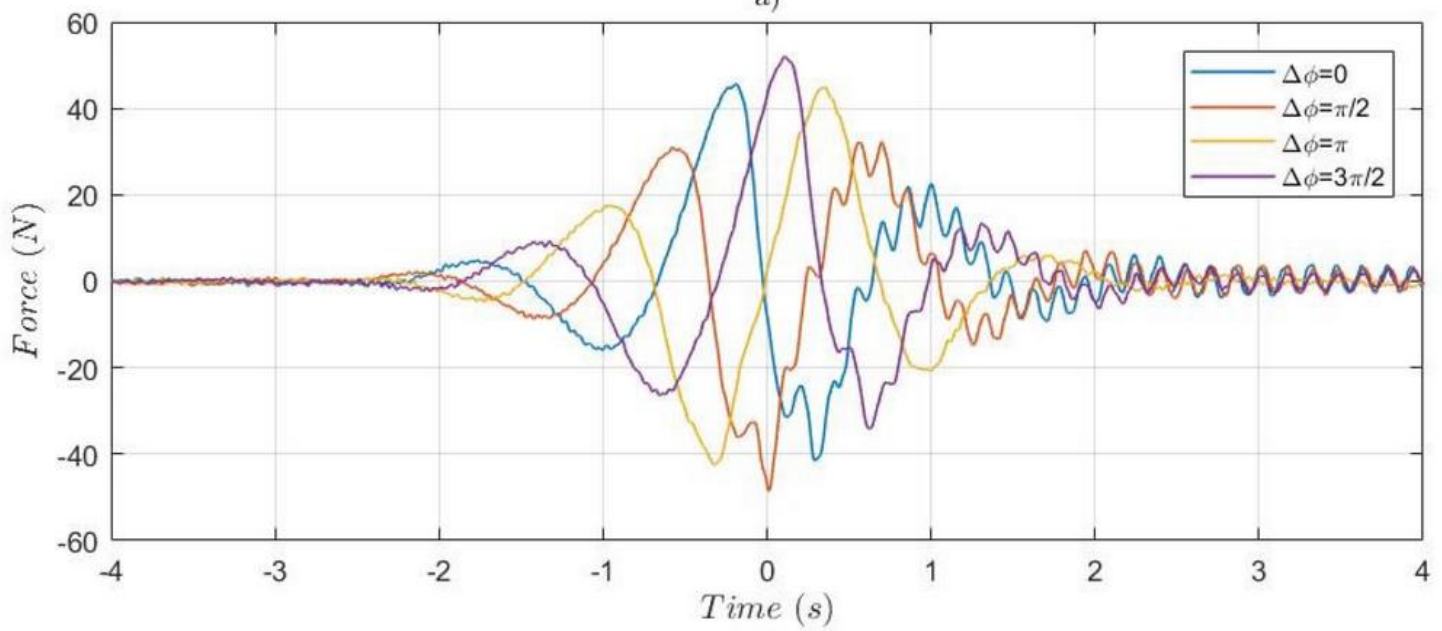

b)

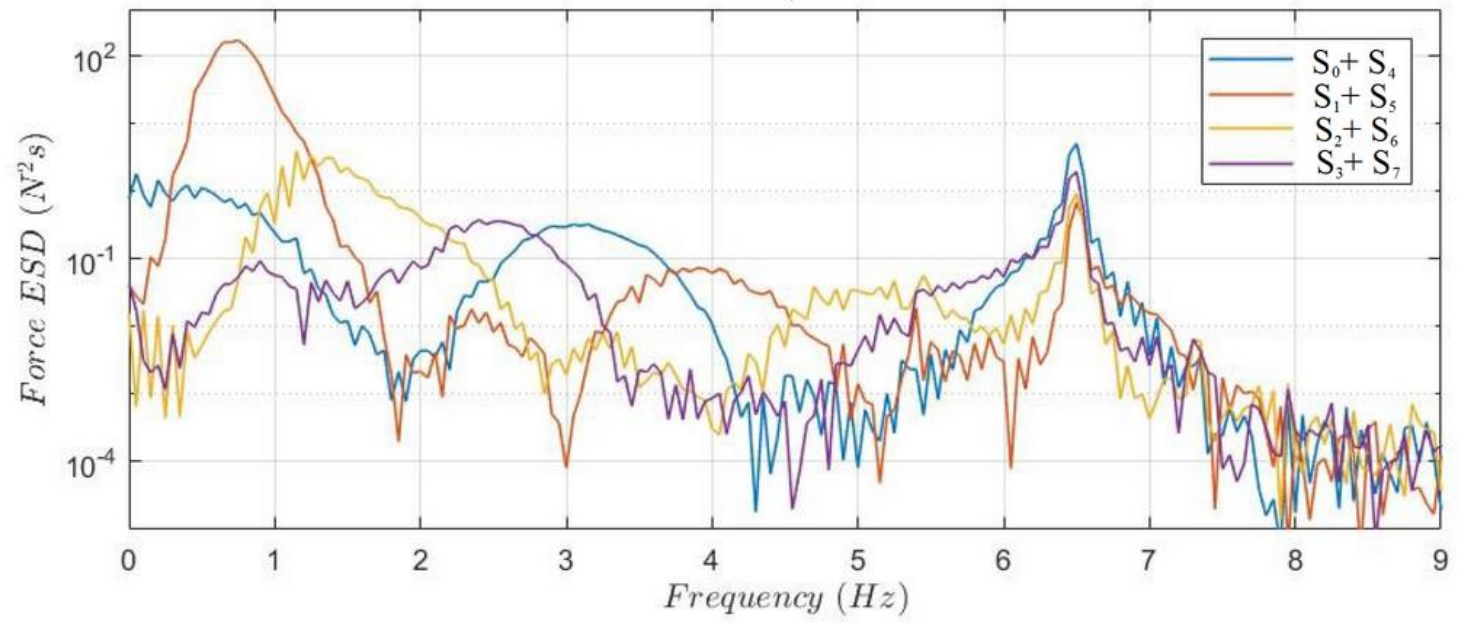

Figure 7: (Colour online) Spectral decomposition of measured horizontal forces for case T14NB2. (a) Signals with different phase shifts $\Delta \phi$. (b) The decomposed spectra.

Further in this section, we compare the force components for high nonbreaking and breaking waves corresponding to different frequency ranges. First, we analyse the harmonic structure of the wave force on the cylinder by applying the spectral decomposition technique described in Section 2. Figure 7 shows an example of applying the decomposition procedure to force measurements. The four force records with phase shifts $\Delta \phi=0$, $\pi / 2, \pi$ and $3 \pi / 2$ are presented in Figure 7(a) and Figure 7(b) illustrates the corresponding decomposed spectra. It can be seen that the spectral components from $S_{0}$ to $S_{5}$ are clearly separated. However, the higher components are affected by the resonant structural response at the first natural frequency. These vibrations contribute to all the decomposed spectral components around the natural frequency. Therefore, the spectral decomposition analysis can no longer be applied. The first structural natural frequency is $6.5 \mathrm{~Hz}$, which is 7.8 and 9.1 times greater than the peak frequencies of the incoming wave spectra for $T_{p}=1.2 \mathrm{sec}$ and $T_{p}=1.4 \mathrm{sec}$, respectively.

The excitation of the resonant structural response by higher components of the wave spectrum is called ringing. Normally, the term applies to the excitation by third harmonic of the incident wave field (e.g. Chandrasekaran, 2017). In our case, ringing is caused by the $6^{\text {th }}, 7^{\text {th }}$ and $8^{\text {th }}$ wave spectrum components. The relatively high first structural natural frequency allows a clear separation of the spectral components up to the fifth order and better understanding of the structural excitation regimes at higher frequencies. Hereafter we consider two frequency ranges. The first one includes frequencies below $5 \mathrm{~Hz}$, where we apply the spectral decomposition. The second range includes higher frequencies, where the decomposition cannot be applied.

Figure 8 show the time histories of the harmonic force components up to the $5^{\text {th }}$ order for steep nonbreaking and breaking waves. It can be seen that there are no major differences between the force harmonics produced by spilling breaking waves and nearly breaking waves which are also highly non-linear and have a similar wave 
a)

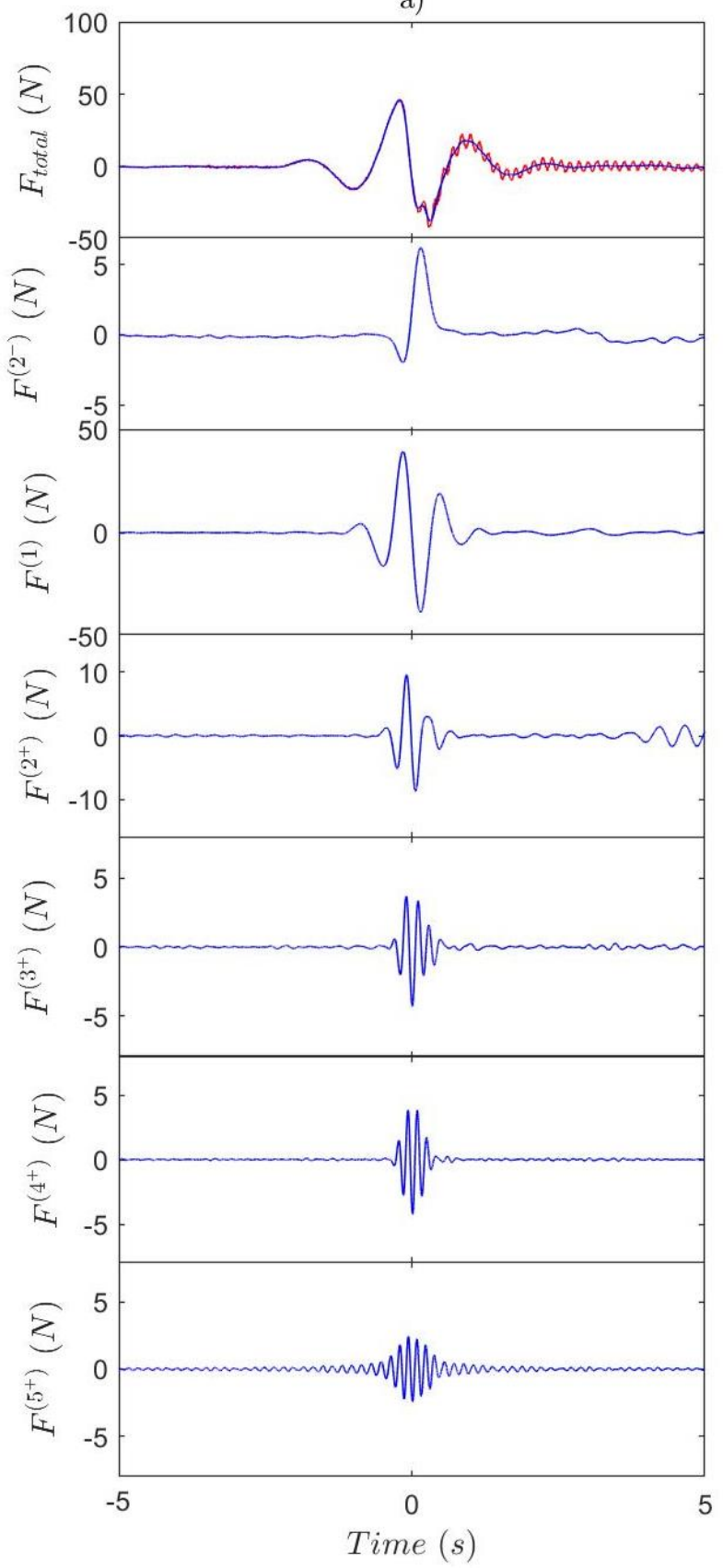

b)

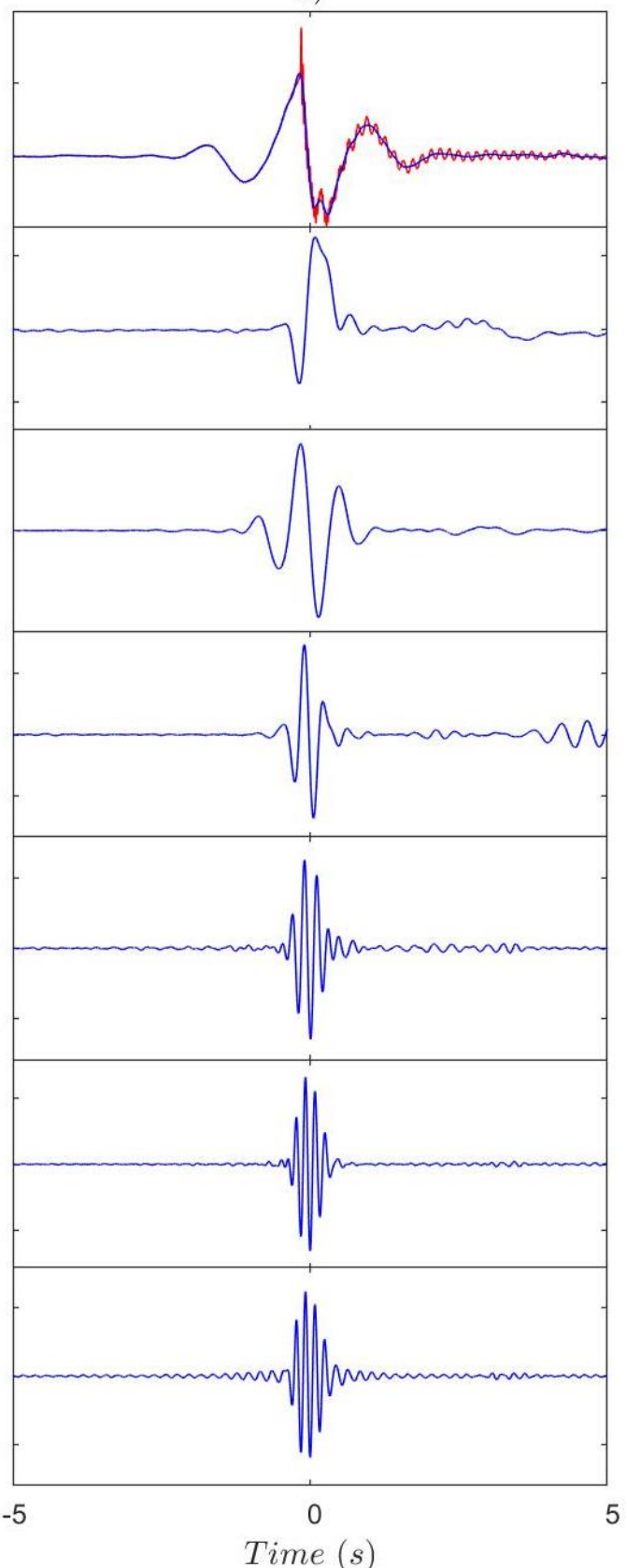

Figure 8: (Colour online) Harmonic structure of the horizontal wave load on the cylinder for cases a) T14NB2 and b) T14BR2. The red line in the first plots shows the original force signal measured.

steepness. The observed harmonic structure of wave loads is close to that reported by Chen et al. (2018) for wave groups with slopes similar to the ones analysed in this study. The amplitude of the high frequency force components decreases slowly for higher harmonics. The reduction in the amplitude of high-order harmonics is significantly slower for breaking waves due to their higher steepness. This leads to a greater contribution of the high-frequency components to the forces produced by the breaking waves.

This fact alone cannot explain the significant increase in force produced by the breaking waves. The comparison of the blue and red lines in the upper row of Figure 8 shows that the forces produced by the combination of spectral components up to the $5^{\text {th }}$ order (blue) are not significantly different for non-breaking and breaking waves of comparable steepness. At the same time, the total force (red) for the breaking wave exhibits a high sharp peak absent for the non-breaking wave. Such behaviour can only be described taking into account significantly higher frequencies than those considered so far. To emphasise this point Figure 9 shows the maximum forces for crest focussed wave groups with filtered and unfiltered frequencies above $5 \mathrm{~Hz}$. The 

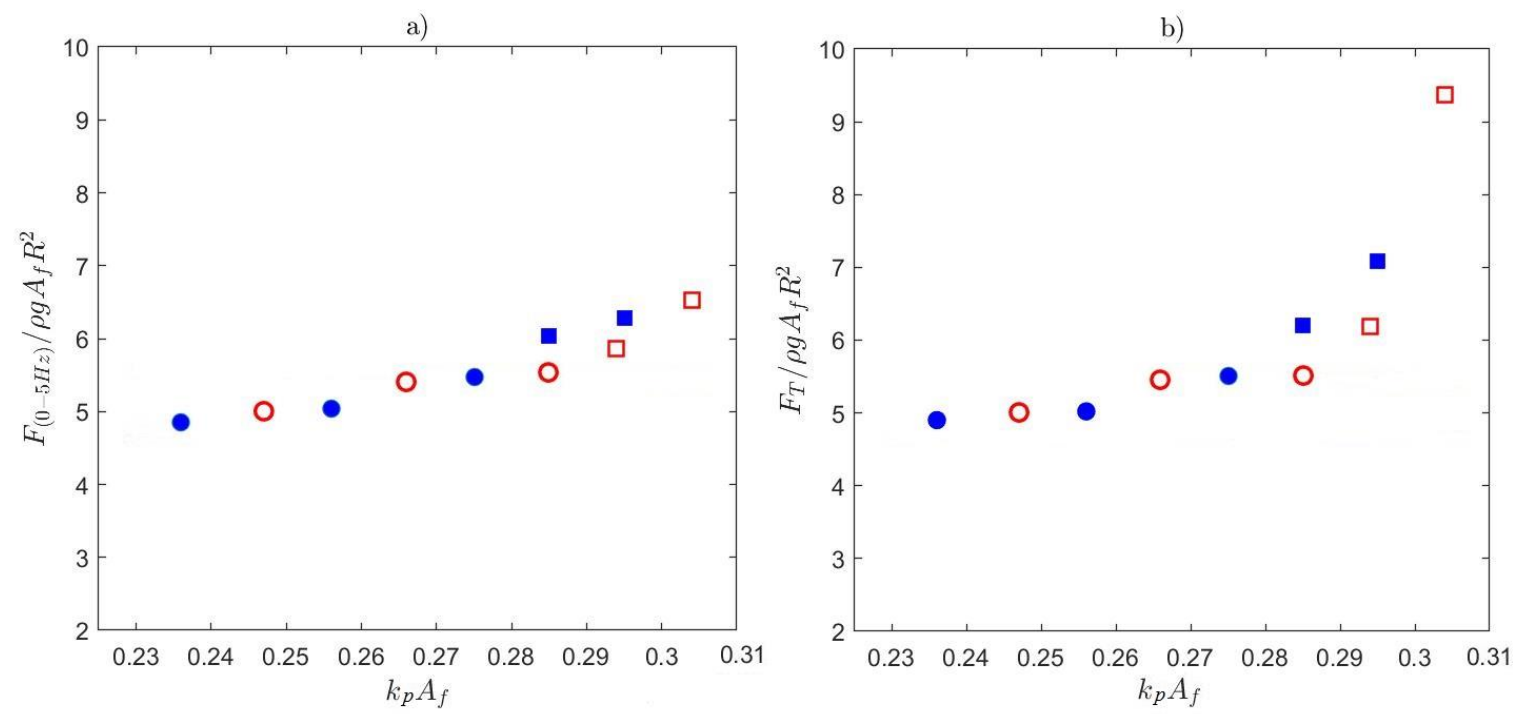

Figure 9: (Colour online) Variation of measured maximum wave forces with wave steepness $k_{p} A_{f .}$ a) Excluding frequencies beyond $5 \mathrm{~Hz}$; b) Including all frequencies. Blue (solid) and red (open) and markers represent measured wave forces for wave groups with $\mathrm{T}_{\mathrm{p}}=1.2 \mathrm{sec}$ and $\mathrm{T}_{\mathrm{p}}=1.4 \mathrm{sec}$, respectively. Circular and square markers represent near-breaking and breaking waves, respectively.

Table 4: Frequency bands to analyse different mechanisms of force generation.

\begin{tabular}{lllllccccc}
\hline & Band & & 1 & & 2 & 3 & 4 & \multicolumn{2}{c}{5} \\
\hline & $\mathrm{f}(\mathrm{Hz})$ & 0 & 5 & 7.5 & 29 & 48 & 75 \\
\hline \multirow{2}{*}{$\mathrm{f} / \mathrm{f}_{\mathrm{p}}$} & $\mathrm{T}_{\mathrm{p}}=1.2 \mathrm{sec}$ & 0 & 6 & 9 & 34.8 & 57.6 & 90 \\
\cline { 2 - 9 } & $\mathrm{T}_{\mathrm{p}}=1.4 \mathrm{sec}$ & 0 & 7 & 10.5 & 40.6 & 67.2 & 105 \\
\hline
\end{tabular}

maximum forces with frequencies lower than $5 \mathrm{~Hz}$ increase almost linearly with wave steepness (Figure 9 a), as can be expected from a regular function over a small range of the argument. Indeed, these results include up to the $5^{\text {th }}$ spectral harmonic and can therefore be adequately described by a $5^{\text {th }}$-order expansion. Such force behaviour would justify the application of DNVGL (2017) recommendations presented in Figure 4. However, Figure 9 (b) shows that taking into account the full range of frequencies causes the forces generated by breaking waves to increase rapidly with the steepness. As a result, for breaking waves, the high frequency contribution accounts for more than $30 \%$ of the total force. This means that qualitatively different physical mechanisms are involved in the generation of force by breaking waves.

To study these mechanisms, we separate the spectral frequencies into several bands linked to the properties of the incoming wave spectrum and to natural structural frequencies. Band boundaries with the corresponding values of $\mathrm{f} / \mathrm{f}_{\mathrm{p}}$ are given in Table 4 . The incoming wave spectra for typical non-breaking and breaking waves for the two wave periods studied can be seen in Figure 10. Frequency band 1 contains the main part of the wave spectrum and does not include natural structural frequencies. A quasi-static wave loading takes place for this spectral band. The harmonic structure of this load has been discussed above. Band 2 still contains a considerable part of the wave energy for all wave groups. It also includes the first natural structural frequency $\mathrm{f}_{1}=6.5 \mathrm{~Hz}$. At this band we can expect the resonant excitation of the structural response at the natural frequency by high harmonics of the wave spectrum (ringing). Band 3 is fundamentally different for breaking and nonbreaking waves presented in Figure 10. For the non-breaking waves, the band has no wave energy higher than the noise level. However, a significant amount of energy can be observed here for the breaking waves. These spectral components are due to the high curvature of the very sharp crests exhibited by such waves. Since there is no natural structural frequency in band 3, the interaction of the wave crest with the cylinder should generate a quasistatic response at this frequency range. Bands 4 and 5 have no spectral components higher than the noise level, but they contain the second and third natural frequencies $\mathrm{f}_{2}=40 \mathrm{~Hz}$ and $\mathrm{f}_{3}=59 \mathrm{~Hz}$ respectively. Forces within these bands can be generated at natural frequencies by the dynamic structural response to the impact of breaking waves.

Figure 11, Figure 12 and Figure 13 support our assumptions about the nature of wave forces generated at different frequency bands. It can be observed that non-breaking waves do not induce high frequency force components beyond the ringing response (band 3) and the ringing responses for non-breaking and breaking waves are not significantly different. However, spilling breaking waves generate considerable forces in the high 


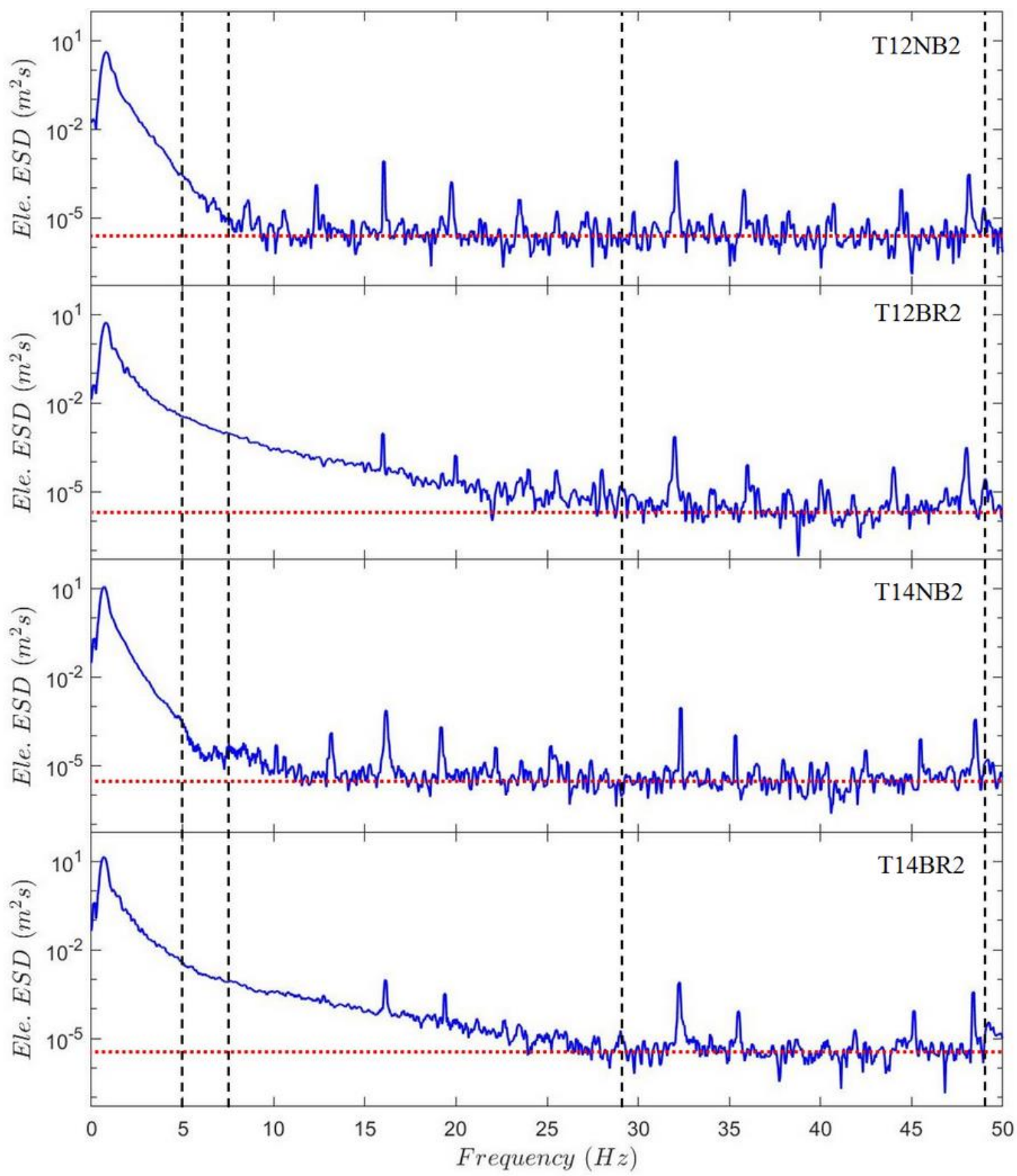

Figure 10: Wave elevation energy spectral density for non-breaking (T12NB2 and T14NB2) and breaking (T12BR2 and T14BR2) cases. Vertical dashed lines separate the frequency bands considered in the analysis. Red dotted line represents the noise level in the measurements.

frequency bands. The dynamic structural response, including ringing (bands 2, 4 and 5), represents approximately $17 \%$ and $28 \%$ of the maximum total force for cases T12BR2 and T14BR2 respectively. The impact response at band 5 is not generated by the weaker breaking wave observed for case T12BR2. In addition to the structural vibrations at natural frequencies, the quasi-static response is observed in band 3 for the two cases of breaking waves. To the authors' knowledge, little is known about the quasi-static loads generated beyond the ringing response. It is difficult to separate the force measurements between the natural structural vibrations and the direct quasi-static excitation by the wave spectral components. This became possible in our experiments because a sufficient amount of wave energy can be found in the spectral components of the waves between the first and second well separated natural frequencies. However, although we were able to identify direct excitation at high frequencies, we found it difficult to separate it entirely from natural vibrations and quantify it accurately.

Figure 14 illustrates the behaviour of high frequency load components in more detail. It represents the force components generated in the frequency bands 2 to 5 with respect to the surface elevation of the incoming 


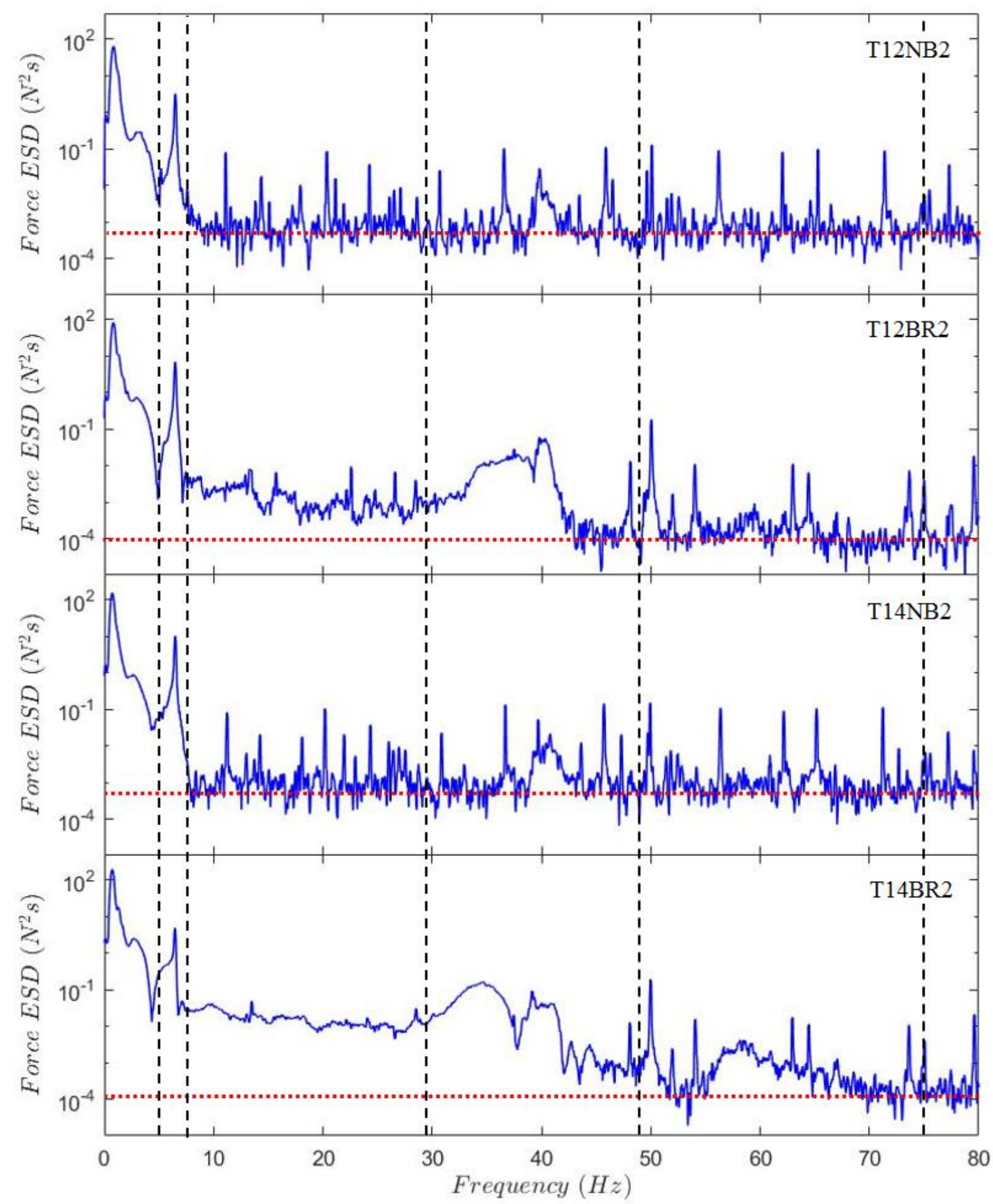

Figure 11: (Colour online) Wave force energy spectral density for non-breaking (T12NB2 and T14NB2) and breaking (T12BR2 and T14BR2) cases. Vertical dashed lines separate the frequency bands considered in the analysis. Red dotted line represents the noise level in the measurements.

wave group. The case T14BR2 is presented, which corresponds to the strongest wave breaking produced in our experiments. The ringing response within frequency band 2 begins to increase before the wave crest reaches the structure and continues growing after it passes. Then, the free oscillations continue with the slow decay due to a weak structural damping. The oscillations grow during the time when the appropriate spectral harmonics (the $6^{\text {th }}$, $7^{\text {th }}$ and $8^{\text {th }}$ ) of the incoming wave interact with the cylinder. A qualitative idea of the quasi-static force that these harmonics would generate on a solid structure can be obtained from the last row of Figure 8(b), which illustrates the $5^{\text {th }}$ force harmonic. A higher quasi-static harmonic has a higher frequency, a smaller amplitude and a shorter duration. In the real case, the resonant growth of the oscillations occurs for the duration of the interaction, which explains the observed ringing behaviour. The breaking wave impact does not produce an immediate visible effect on these oscillations. However, it can be responsible for the modulation observed in the decaying part of the 
a)

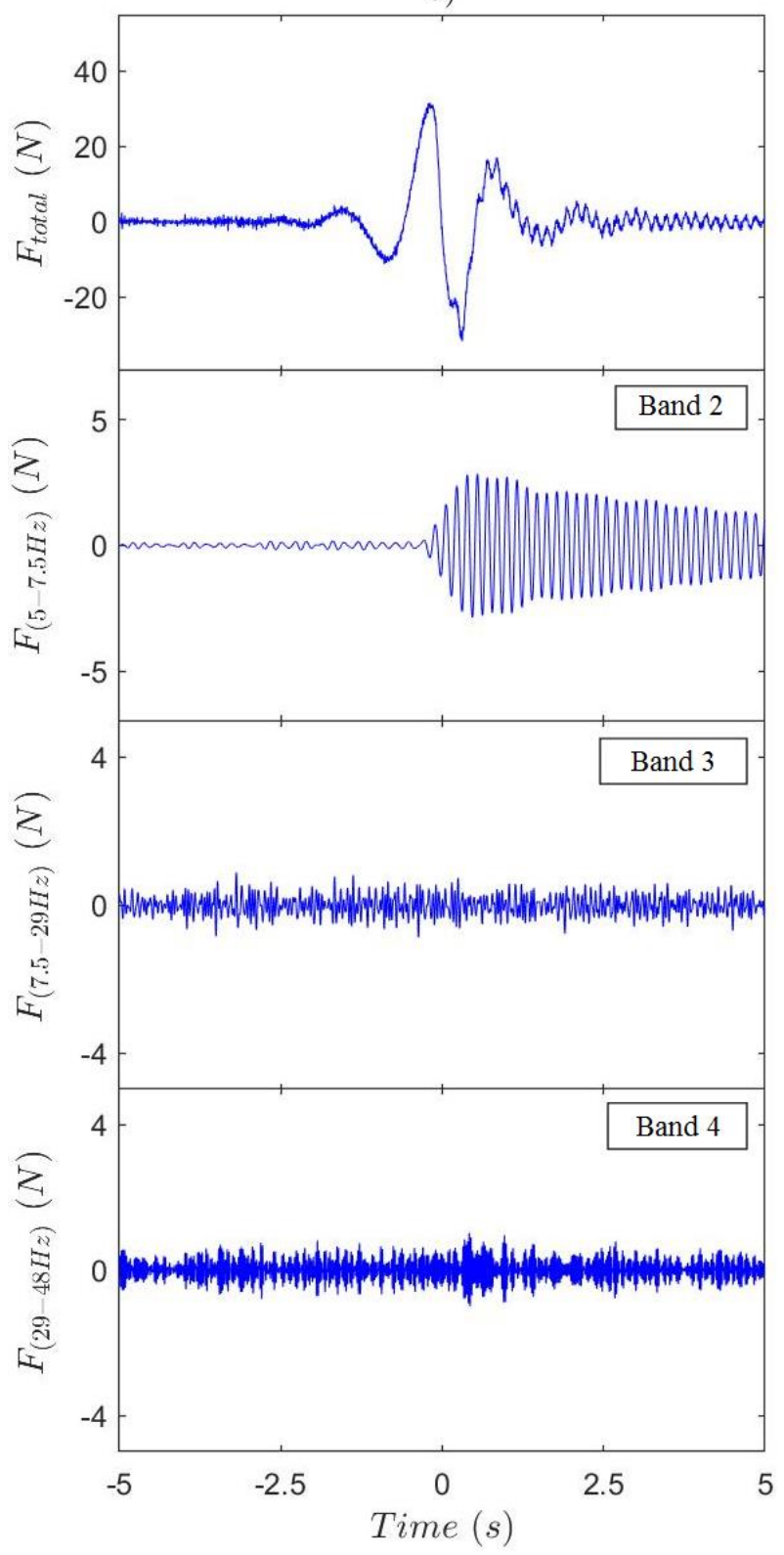

b)

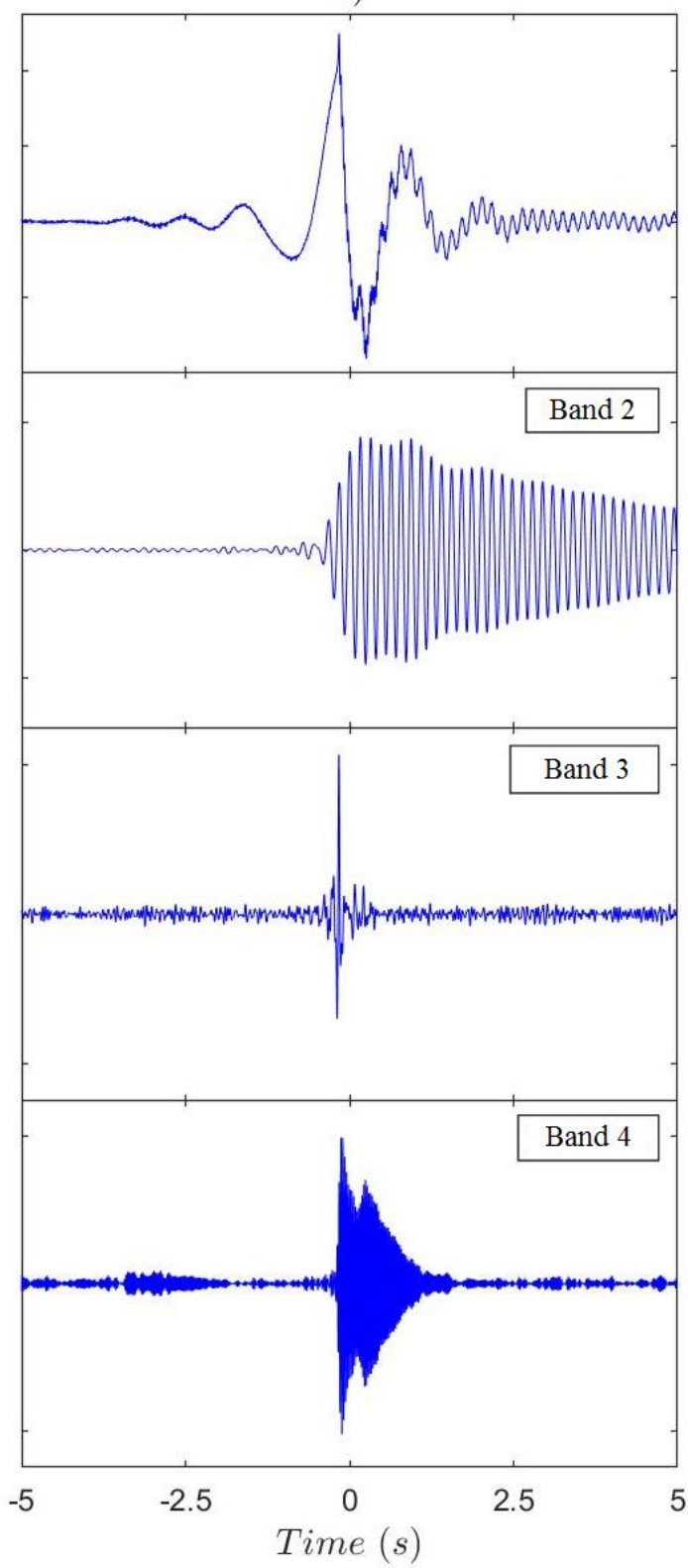

Figure 12: The high frequency components of the horizontal wave force on the cylinder for focused wave groups for cases a) T12NB2 (non-breaking) and b) T12BR2 (breaking).

ringing vibrations. This assumption is supported by the fact that the non-breaking wave produces practically no modulation of the ringing vibrations (Figure 13).

The quasi-static response in frequency band 3 is localised around the wave crest. The response includes a distinct peak preceded and followed by considerable troughs, then decreases rapidly to almost zero. The dominant part of the force signal in band 3 seen in Figure 14 includes two complete oscillations with a total duration of approximately $0.1 \mathrm{~s}$. This time is close to the time required for the crest to move past the front face and reach the rear side of the cylinder. One can suggest several mechanisms for the generation of this force. First, it is the drag generated by the high fluid velocity near the water surface in the vicinity of the sharp wave crest. This velocity decreases rapidly away from the crest. Therefore, the associated drag exhibits fast growth and decay while the crest moves past the cylinder. Another force generation mechanism is due to the change of the fluid momentum caused by the change of the wetted surface of the cylinder. This is the surface intersection force which, in the case of a small angle between the axis of the cylinder and the water surface is known as the slam load (Rainey, 1989; Rainey, 1995). Then, a force can be produced by the asymmetric deformation of the water surface by the cylinder in the vicinity of the crest, which can be related to the surface distortion force discussed by Chaplin et al. (1997). The works cited above use a slender cylinder approximation and the Stokes expansion to estimate 
a)

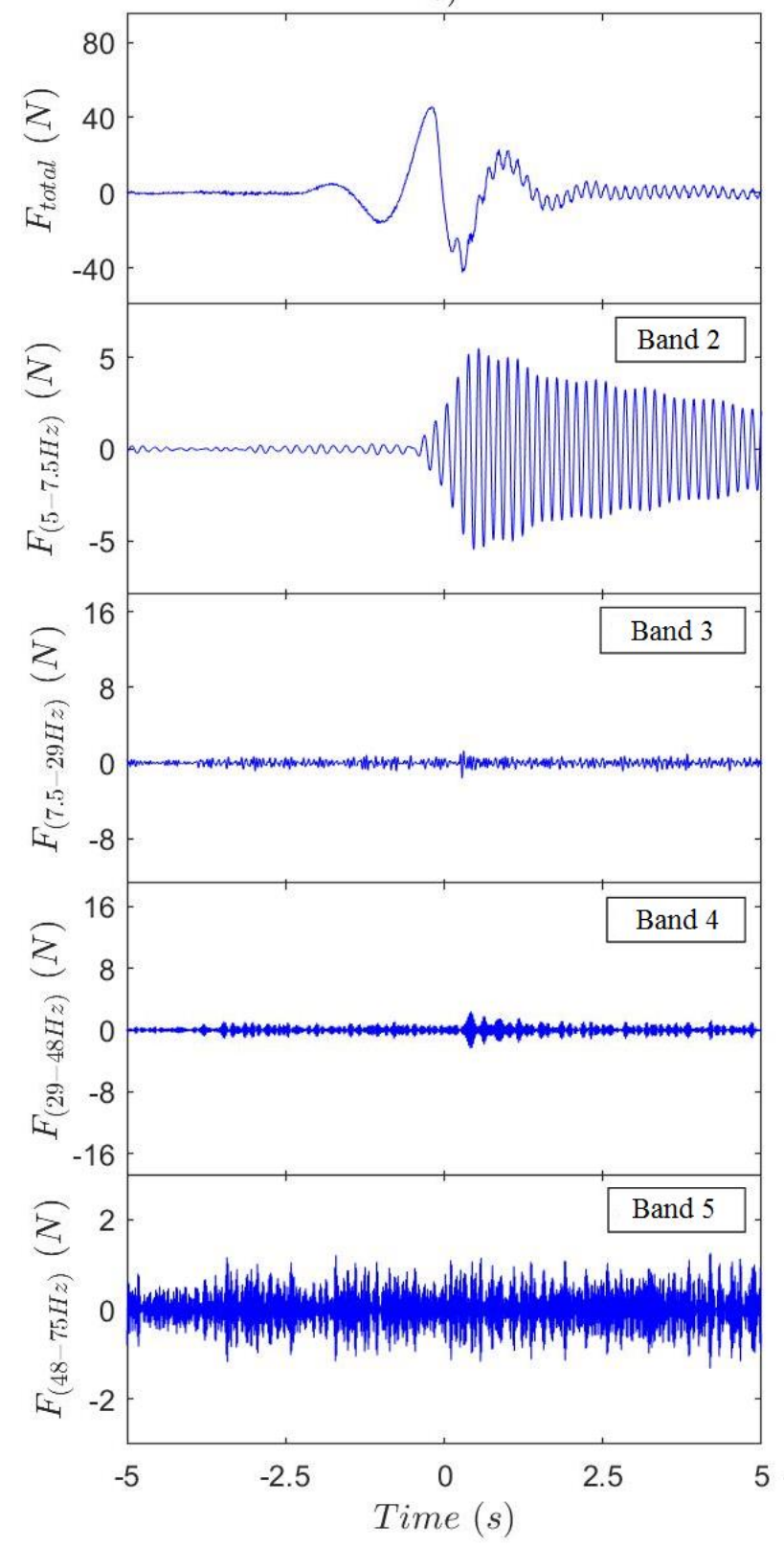

b)

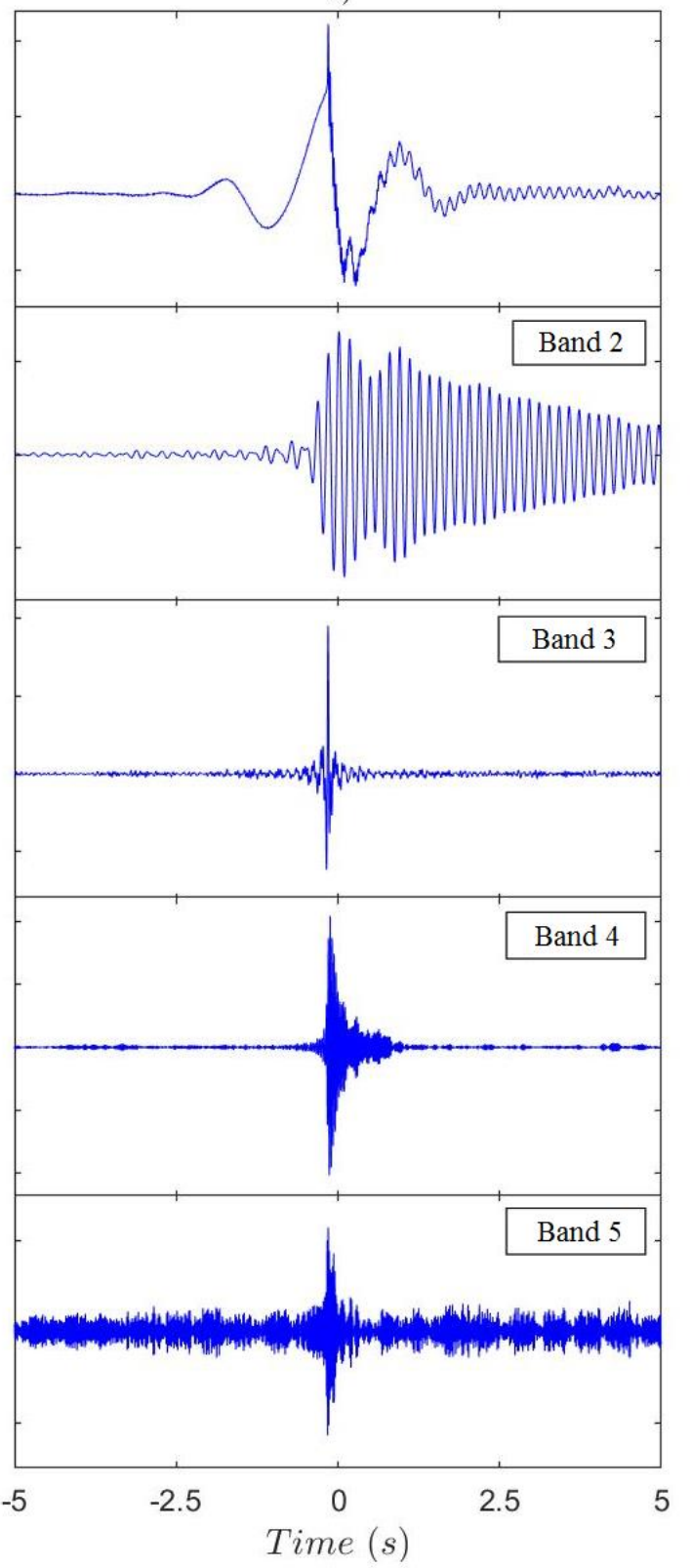

Figure 13: The high frequency components of the horizontal wave force on the cylinder for focused wave groups for cases a) T14NB2 (non-breaking) and b) T14BR2 (breaking).

the values of the surface intersection and surface distortion forces. These approximations are not strictly valid in our case of the strongly nonlinear wave with a crest radius comparable to or less than the diameter of the cylinder. However, they do provide valuable qualitative insight into the possible mechanisms of force generation. Finally, we can expect to find a diffractive element in the force due to the transfer of momentum by high frequency waves radiated by the cylinder during its interaction with the wave crest. It should be noted that the force generation mechanisms discussed here are not directly related to wave breaking. They will also apply to non-breaking waves with a sufficiently small crest radius. However, the small radius of the wave crest is normally associated with spilling breaking that has just occurred or is about to occur.

The forces for frequency bands 4 and 5 exhibit qualitatively similar behaviour. The amplitude of the force oscillations begins to increase slowly before the wave crest reaches the cylinder. This can be explained by the weak ringing response at the natural frequency caused by the high frequency wave components, which are below the noise level and therefore cannot be seen in Figure 10. When the wave crest reaches the cylinder, the amplitude of the natural vibrations shows a significant instantaneous increase due to the impact of the breaking wave crest. After that, free oscillations at the natural frequency can be observed. These oscillations decay quickly due to the high damping for the corresponding structural vibration modes. The modulation of free oscillations can 


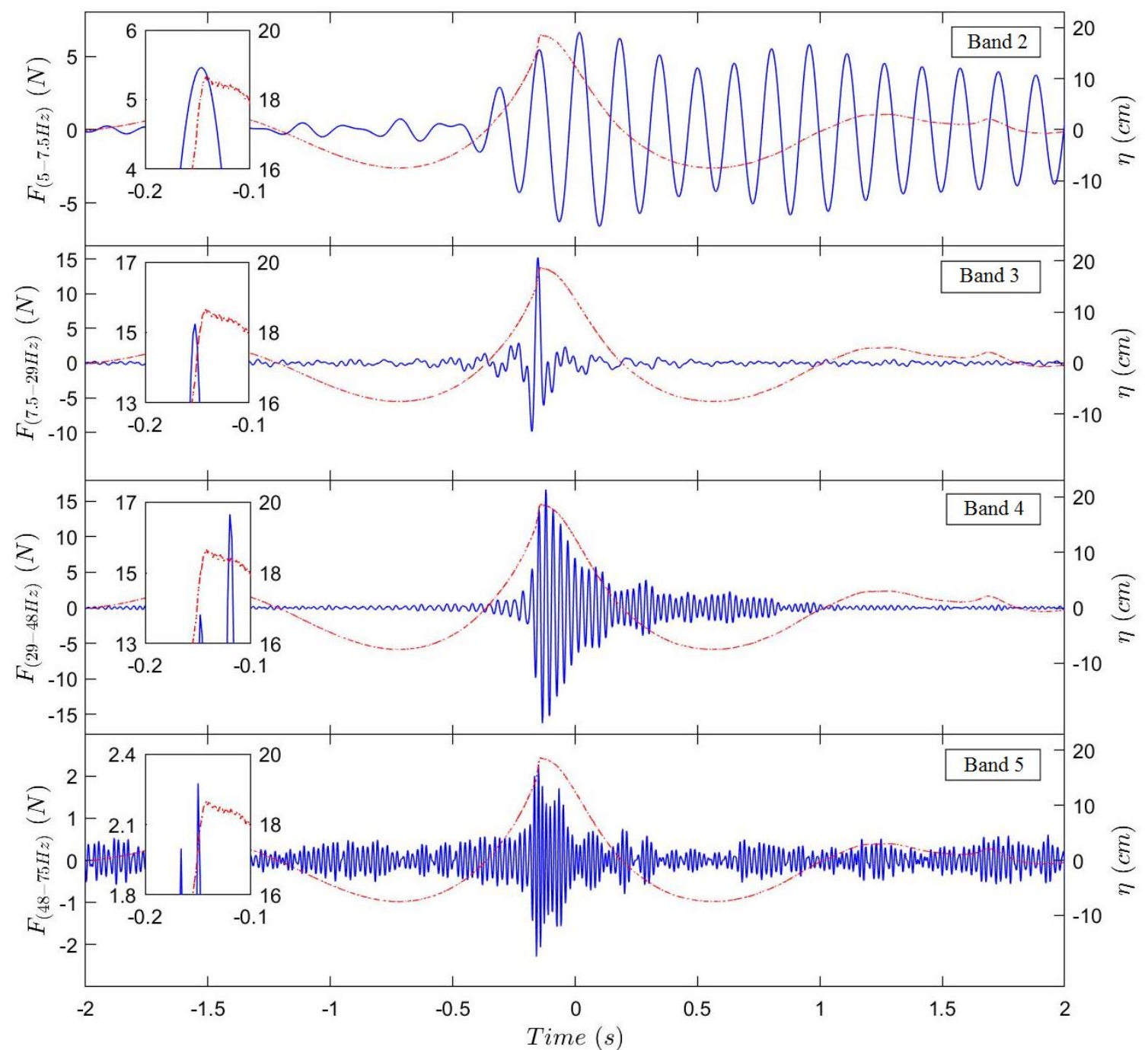

Figure 14: (Colour online) High frequency components of the horizontal force for case T14BR2 (blue). The red dashed line shows the corresponding surface elevation.

be explained by the interference between ringing and impact vibrations. In total, the dynamic force response at the high natural frequencies due to the breaking impact is almost 3 times greater than the ringing response at the first natural frequency.

\section{Conclusions}

A series of experiments has been carried out in a wave tank to study high-frequency wave forces imposed by nearly breaking and spilling breaking waves. Highly nonlinear waves have been generated using the focused wave group methodology proposed by Buldakov et al. (2017). The modelled transient wave group had a Gaussian spectrum and two cases with different peak frequencies were generated. The magnitude of impact forces depends on the quality of focusing achieved during the wave group generation because the waves slam against the structure and very small deviations can cause significant differences in the measured impact force. Therefore, using adequate focusing methods is critical. The method used in this study successfully achieved the generation of highly nonlinear focussed waves, both non-breaking and spilling breaking. For the spectral decomposition of the forces, a four wave decomposition method adopted by Buldakov et al. (2017) was used. It has been demonstrated that this method is applicable even for spilling breaking wave forces and results between non-breaking and breaking waves are consistent.

It was found that the present method could successfully generate steep non-breaking and spilling breaking waves of practically identical spectra for focused wave groups of increasing amplitude. However, it was not possible to achieve good quality focused wave groups with stronger breakers than the ones shown in this study as the wave group was found to break before arriving at the focus position. Spilling breaking appears for wave groups 
with a steepness $\mathrm{k}_{\mathrm{p}} \mathrm{A}_{\mathrm{f}}=0.28-0.29$, which is consistent with the results of Chaplin (1996). The corresponding measured wave height to wavelength ratio $\mathrm{H} / \lambda=0.08-0.09$ is low compared to the widely used value of MicheStokes breaking limit $(H / \lambda=0.14$ in deep water) recommended, for example, by DNVGL (2017). Therefore, spilling breaking waves could occur at conditions where DNVGL (2017) recommendations do not predict breaking. This conclusion is supported by field observations. For example, Fedele et al. (2019) in their analysis of sea states with the steepness of highest waves $\mathrm{H} / \lambda=0.11$ found that these waves were near the onset of incipient breaking or already breaking. They concluded that the onset of wave-breaking can occur well below the MicheStokes upper limit. Moreover, it is also documented that breaking occurs even at lower steepness. For example, Holthuijsen \& Herbers (1986) in their wave-by-wave analysis of buoy data in open sea conditions coupled with visual observations of breaking events found that waves break at steepness values much less than the conventionally expected theoretical value. The reported average steepness of breaking waves is only $\mathrm{H} / \lambda=0.042$. Tulin \& Li (1992) suggested that breaking waves at sea are generated by unsteady wave interactions and cannot be directly related to a limiting wave steepness.

The main focus of this study is to analyse and compare wave forces imposed by highly nonlinear nonbreaking waves and spilling breaking waves. It has been shown that the maximum forces induced by spilling breaking waves are considerably larger than the forces from nearly breaking highly non-linear waves. This can have a critical effect on the design of offshore structures as spilling breaking waves are very common in extreme environments. Using high order nonlinear wave theories might underestimate the maximum load imposed by spilling breaking waves. It has been shown that loading from steep non-breaking waves can be adequately described by taking into account up to the $5^{\text {th }}$ spectral harmonic. Such flow can therefore be simulated by a $5^{\text {th }}$ order expansion theory. However, this simplification significantly underestimates the total wave force imposed by spilling breaking wave groups.

To study the high frequency response, we separate the spectral frequencies into bands related to the incoming wave spectrum and to natural structural frequencies. The frequency range considered extends up to 100 times of the wave peak frequency and includes 3 natural structural frequencies. Different types of structural response are observed in different frequency bands, including the quasi-static response, the ringing and the excitation of natural structural vibrations by the impact of breaking waves. It is found that the non-breaking waves do not induce high frequency force components beyond the ringing response at the first natural frequency. The ringing response is similar for non-breaking and breaking waves. The spilling breaking waves generate considerable forces in the high frequency bands. The dynamic force response for the strongest breaking wave generated represents up to $28 \%$ of the maximum total force. Moreover, the impact response at the high natural frequencies is almost 3 times greater than the ringing response at the first natural frequency. In addition, the high frequency quasi-static response is observed between the first and second natural frequencies.

An important question is scaling of test results to full scale. Force components in different frequency bands considered in the paper are governed by different physical processes and therefore obey different scaling laws. The quasi-static response of band 1 corresponds to the inertia dominated load and can be successfully scaled using conventional Froude similarity. On a scale of 1/100 our band 1 results can be applied to sea states with peak periods of 12 and $14 \mathrm{~s}$ at $100 \mathrm{~m}$ depth to a tower of $16.5 \mathrm{~m}$ in diameter. Further, if the ratios of natural structural frequencies to the peak spectral frequency of the wave are the same for the model and for the full-scale structure (e.g. Suja-Thauvin et al., 2017), then the ringing response can be scaled in a similar manner. In our experiments this corresponds to frequency band 2 . The response in band 3 is caused by the combined action of the drag and the deformation of the free surface. Proper scaling of these processes would have to follow Froude and Reynolds similarity laws, which is practically impossible. The usual approach is to run tests at multiple increasing scales using Froude scaling and select a scale when the further increase in Reynolds number stops affecting the results. We believe that the Reynolds number in our experiment is not high enough and that large-scale experiments are needed for an accurate quantitative description of the Band 3 response.

The response in high frequency bands is mostly generated by the breaking wave impact and the corresponding scaling should be applied to these results. The difficulties of scaling breaking waves impact have long been recognized (e.g. Chan \& Melville, 1989). Most of the works dealing with the scale effects of wave impact consider the impact of a plunging wave on a vertical wall. The results based on the analysis of a large air pocket trapped between the overturning wave and the wall (e.g. Cuomo et al., 2010) can hardly be applied to the impact of a spilling breaking wave on a cylinder. However, works considering aeration of the water before impact may provide insight into the problem (e.g. Bullock et al., 2001; Bredmose et al., 2015). These and other studies show that the level of aeration has a significant influence on the impact. In turn, the level of aeration is related to 
the dynamics of a spilling crest and largely depends on surface tension (e.g. Stagonas et al., 2011). In addition, the size of the air bubbles depends on the salinity of the water. The salinity of the water, however, has only a minor effect on the maximum impact pressure (e.g. Bullock et al., 2001) and is even less important for the integral response such as force. Therefore, the shape and aeration of the wave crest before impact depends on surface tension and is controlled by the Weber number. Achieving similarity by this parameter is as difficult as achieving Reynolds similarity and a similar approach of running tests at increasing Froude scales may be recommended.

It is concluded that the forces imposed by spilling breaking waves can have a significant impact in the design of offshore structures. They lead both to an increase of the total wave load and to the generation of high frequency structural vibrations, which can cause fatigue damage in offshore structures.

\section{Acknowledgment}

The authors would like to thank Mr. Keith Harvey and Mr. Les Ansdell, technicians from the UCL Civil Engineering Fluids Lab, for their invaluable help in carrying out the experiments presented in this work.

\section{References}

Aggarwal, A., Bihs, H., Myrhaug, D., \& Chella, M. A. (2019). Characteristics of breaking irregular wave forces on a monopile. Applied Ocean Research, 90(art. no. 101846). https://doi.org/10.1016/j.apor.2019.06.003

Alagan Chella, M., Bihs, H., \& Myrhaug, D. (2019). Wave impact pressure and kinematics due to breaking wave impingement on a monopile. Journal of Fluids and Structures, 86, 94-123. https://doi.org/10.1016/0378-3839(87)90015-9

Alagan Chella, M., Bihs, H., Myrhaug, D., \& Muskulus, M. (2015). Breaking characteristics and geometric properties of spilling breakers over slopes. Coastal Engineering, 95, 4-19. https://doi.org/10.1016/j.coastaleng.2014.09.003

Alagan Chella, M., Tørum, A., \& Myrhaug, D. (2012). An overview of wave impact forces on offshore wind turbine substructures. Energy Procedia, 20, 217-226. https://doi.org/10.1016/j.egypro.2012.03.022

Apelt, C. J., \& Piorewicz, J. (1987). Laboratory studies of breaking wave forces acting on vertical cylinders in shallow water. Coastal Engineering, 11(3), 263-282. https://doi.org/10.1016/0378-3839(87)90015-9

Baldock, T., \& Swan, C. (1996). Extreme waves in shallow and intermediate water depths. Coastal Engineering, 27, 21-46. https://doi.org/10.1016/0378-3839(95)00040-2

Baldock, Tom, Swan, C., \& Taylor, P. H. (1996). A Laboratory Study of Nonlinear Surface Waves on Water. Proceedings of The Royal Society A Mathematical Physical and Engineering Sciences, 354(March), 649676. https://doi.org/10.1098/rsta.1996.0022

Boccotti, P. (1982). On ocean waves with high crests. Meccanica, 17(1), 16-19. https://doi.org/10.1007/BF02156003

Bredmose, H., Bullock, G. N., \& Hogg, A. J. (2015). Violent breaking wave impacts. Journal of Fluid Mechanics, 765, 82-113. https://doi.org/10.1017/jfm.2014.692

Buldakov, E., Stagonas, D., \& Simons, R. (2017). Extreme wave groups in a wave flume: Controlled generation and breaking onset. Coastal Engineering, 128, 75-83. https://doi.org/10.1016/j.coastaleng.2017.08.003

Bullock, G. N., Crawford, A. R., Hewson, P. J., Walkden, M. J. A., \& Bird, P. A. D. (2001). The influence of air and scale on wave impact pressures. Coastal Engineering, 42(4), 291-312. https://doi.org/ 10.1016/S0378-3839(00)00065-X

Chakrabarti, S. K., Kriebel, D., \& Berek, E. P. (1997). Forces on a single pile caisson in breaking waves and curret. Applied Ocean Research, 19(2), 113-140. https://doi.org/10.1016/S0141-1187(97)00016-3

Chan, E.-S., Cheong, H.-F., \& Tan, B.-C. (1995). Laboratory study of plunging wave impacts on vertical cylinders. Coastal Engineering, 25(1-2), 87-107. https://doi.org/10.1016/0378-3839(94)00042-V

Chan, E.-S., \& Melville, W. K. (1989). Plunging wave forces on surface-piercing structures. Journal of Offshore Mechanics and Artic Engineering, 111(2), 92-100. https://doi.org/10.1115/1.3257093

Chandrasekaran, S. (2017). Dynamic Analysis and Design of Offshore Structure. Springer. 
Chaplin, J R, Rainey, R. C. T., \& Yemm, R. W. (1997). Ringing of a vertical cylinder in waves. Journal of Fluid Mechanics, 350, 119-147. https://doi.org/10.1017/S002211209700699X

Chaplin, John R. (1996). On Frequency-Focusing Unidirectional Waves. International Journal Offshore Polar Engineering, 6(2), 131-137.

Chen, L. F., Zang, J., Taylor, P. H., Sun, L., Morgan, G. C. J., Grice, J., Orszaghova, J., \& Tello Ruiz, M. (2018). An experimental decomposition of nonlinear forces on a surface-piercing column : Stokes-type expansions of the force harmonics. Journal of Fluid Mechanics, 848, 42-77. https://doi.org/10.1017/jfm.2018.339

Choi, S.-J., Lee, K.-H., \& Gudmestad, O. T. (2015). The effect of dynamic amplification due to a structure's vibration on breaking wave impact. Ocean Engineering, 96, pp-8-20. https://doi.org/10.1016/j.oceaneng.2014.11.012

Christou, M., \& Ewans, K. (2014). Field Measurements of Rogue Water Waves. Journal of Physical Oceanography, 44(9), 2317-2335. https://doi.org/10.1175/jpo-d-13-0199.1

Cuomo, G., Allsop, W., \& Takahashi, S. (2010). Scaling wave impact pressures on vertical wall. Coastal Engineering, 57(6), 604-609. https://doi.org/10.1016/j.coastaleng.2010.01.004

DNVGL. (2017). DNV-RP-C205 : Environmental conditions and environmental loads. DNV GL AS.

Fedele, F., Herterich, J., Tayfun, A., \& Dias, F. (2019). Large nearshore storm waves off the Irish coast. Scientific Reports, 9(1), art. no. 15406. https://doi.org/10.1038/s41598-019-51706-8

Fernández, H., Sriram, V., Schimmels, S., \& Oumeraci, H. (2014). Extreme wave generation using self correcting method - Revisited. Coastal Engineering, 93, 15-31. https://doi.org/10.1016/j.coastaleng.2014.07.003

Fitzgerald, C. J., Taylor, P. H., \& Taylor, R. E. (2014). Phase manipulation and the harmonic components of ringing forces on a surface-piercing column. Proceedings of The Royal Society, A 470, 1-21. https://doi.org/10.1098/rspa.2013.0847

Ghadirian, A., Bredmose, H., \& Dixen, M. (2016). Breaking phase focused wave group loads on offshore wind turbine monopiles. Journal of Physics: Conference Series, 753(9), art. no. 092004. https://doi.org/10.1088/1742-6596/753/9/092004

Grue, J., Bjorshol, G., \& Strand, O. (1993). Higher harmonic wave exciting forces on a vertical cylinder. Mech. Appl. Math., Preprint series.

Hildebrandt, A., \& Schlurmann, T. (2012). Breaking wave kinematics, local pressure, and forces on a tripod support structure. Proceedings of the 33rd International Coastal Engineering Conference, 3768-3781.

Holthuijsen, L. H., \& Herbers, T. H. C. (1986). Statistics of Breaking Waves Observed as Whitecaps in the Open Sea. Journal of Physical Oceanography, 16(2), 290-297. https://doi.org/10.1175/15200485(1986)016<0290:SOBWOA>2.0.CO;2

Huseby, M., \& Grue, J. (2000). An experimental investigation of higher-harmonic wave forces on a vertical cylinder. Journal of Fluid Mechanics, 414, 75-103. https://doi.org/10.1017/S0022112000008533

Kim, N., \& Kim, C. H. (2003). Investigation of a dynamic property of Draupner freak wave. International Journal Offshore and Polar Engineering, 13(1), 38-42.

Lindgren, G. (1970). Some Properties of a Normal Process Near a Local Maximum. The Annals of Mathematical Statistics, 40(6), 1870-1883. https://doi.org/10.1214/aoms/1177696688

Luck, M., \& Benoit, M. (2005). Wave loading on monopile foundation for offshore wind turbines in shallowwater areas. Proceedings of the 19th International Coastal Engineering Conference, 3992-4004. https://doi.org/10.1142/9789812701916-0322

Phillips, O. M., Gu, D., \& Donelan, M. (1993). Expected Sturcture of Extreme Waves in a Gaussian Sea. Part I: Theory and SWADE Buoy Measurements. In Journal of Physical Oceanography (Vol. 23, pp. 992-1000). https://doi.org/10.1175/1520-0485(1993)023<0992:ESOEWI>2.0.CO;2

Rainey, R. C. T. (1989). A new equation for calculating wave loads on offshore structures. Journal of Fluid Mechanics, 204(WW3), 295-324. https://doi.org/10.1017/S002211208900176X 
Rainey, R. C. T. (1995). Slender-body expressions for the wave load on offshore structures. Proceedings of Royal Society of London, 450(1939), 391-416. https://doi.org/10.1098/rspa.1995.0091

Rapp, R. J., \& Melville, W. K. (1990). Laboratory Measurements of Deep-Water Breaking Waves. Trans. R. Soc. London, 331, 735-800. https://doi.org/10.1098/rsta.1990.0098

Schmittner, C., Kosleck, S., \& Hennig, J. (2009). A Phase-Amplitude Iteration Scheme for the Optimization of Deterministic wave sequences. Proceedings of the International Conference in Offshore and Artic Engineering, 6, 653-660. https://doi.org/10.1115/OMAE2009-80131

Stagonas, D., Buldakov, E., \& Simons, R. (2014). Focusing unidirectional wave groups on finite water depth with and without currents. Proceedings of the 34th International Coastal Engineering Conference (ICCE), January. https://doi.org/10.9753/icce.v34.waves.31

Stagonas, D., Warbrick, D., Muller, G., \& Magagna, D. (2011). Surface tension effects on energy dissipation by small scale, experimental breaking waves. Coastal Engineering, 58(9), 826-836. https://doi.org/10.1016/j.coastaleng.2011.05.009

Stansby, P. K., Devaney, L. C., \& Stallard, T. J. (2013). Breaking wave loads on monopiles for offshore wind turbines and estimation of extreme overturning moment. IET Renewable Power Generation, 7(5), 514520. https://doi.org/10.1049/iet-rpg.2012.0205

Suja-Thauvin, L., Krokstad, J. R., Bachynski, E. E., \& de Ridder, E.-J. (2017). Experimental results of a multimode monopile offshore wind turbine support structure subkected to steep and breaking irregular waves. Ocean Engineering, 146, 339-351. https://doi.org/10.1016/j.oceaneng.2017.09.024

Ting, F. C. K., \& Kirby, J. T. (1996). Dynamics of surf-zone turbulence in a spilling breaker. Coastal Engineering, 27(3-4), 131-160. https://doi.org/10.1016/0378-3839(95)00037-2

Tromans, P. S., Anaturk, A. R., \& Hagemeijer, P. (1991). A new model for the kinematics of large ocean waves - application as a design wave. Proceedings of the First International Offshore and Polar Engineering Conference, 64-71.

Tulin, M. P., \& Li, J. J. (1992). On the breaking of energetic waves. International Journal of Offshore and Polar Engineering, 2(1), 46-53.

Wienke, J., \& Oumeraci, H. (2005). Breaking wave impact force on a vertical and inclined slender pile Theoretical and large-scale model investigations. Coastal Engineering, 52(5), 435-462. https://doi.org/10.1016/j.coastaleng.2004.12.008 